\title{
Public attitude toward and perceptions of dairy cattle welfare in cow-calf management systems differing in type of social and maternal contact
}

\author{
L. V. Sirovica, ${ }^{1}$ ○ C. Ritter, ${ }^{1,2} \odot$ J. Hendricks, ${ }^{1}$ D. M. Weary, ${ }^{1} \odot$ S. Gulati, ${ }^{3}$ and M. A. G. von Keyserlingk ${ }^{1 *}$ () \\ ${ }_{1}^{1}$ Animal Welfare Program, Faculty of Land and Food Systems, University of British Columbia, 2357 Main Mall, Vancouver, BC, V6T 1Z6, Canada \\ ${ }^{2}$ Atlantic Veterinary College, University of Prince Edward Island, 5550 University Ave., Charlottetown, PE, C1A43, Canada \\ ${ }^{3}$ Wildlife and Conservation Economics Laboratory, Faculty of Land and Food Systems, University of British Columbia, 2357 Main Mall, Vancouver, \\ BC, V6T 1Z6, Canada
}

\section{ABSTRACT}

Early cow-calf separation followed by individual housing of calves is standard practice on dairy farms. However, a growing body of evidence suggests that as awareness grows the public will oppose these practices, which could compromise the dairy industry's social license. Despite disagreement among different stakeholders over weighting and evaluations of effects of early separation (e.g., distress response, disease risk), recent systematic reviews indicate that there is little scientific evidence supporting this practice. The acceptability of alternative cow-calf management systems is unknown. We used a mixed methods survey with a convenience sample of 307 Canadians plus a representative sample of 1,487 Americans to investigate perceptions of these systems, examining the effects of providing social or foster cow contact following early separation or not separating cow-calf pairs. Attitudes and perceptions of animal welfare were more positive (on a 7 -point scale where 1 is most negative, 7 is most positive, and 4 is a neutral midpoint) toward the system where calves were not separated from the cow (mean \pm SE; $5.8 \pm$ $0.07 ; 5.7 \pm 0.07$ ), compared with systems in which the calf was separated and individually housed (3.6 \pm 0.07 ; $3.4 \pm 0.07)$, separated and group housed $(3.7 \pm 0.07$; $3.4 \pm 0.07$ ), or separated and kept with a foster cow $(3.8 \pm 0.07 ; 3.6 \pm 0.07)$. Participants were consistent in their attitudes toward and perceptions of animal welfare within the system, suggesting that participants took a holistic and value-oriented approach to cow-calf management regarding separation. These results, in combination with many participants' concern for the importance of the mother cow-calf relationship and perceptions that severing of this bond was a breach of standard of care, suggest that there may be low acceptance of any cow-calf management system involving

Received September 26, 2021.

Accepted November 29, 2021.

*Corresponding author: marina.vonkeyserlingk@ubc.ca early separation as such systems are unlikely to resonate with underlying values.

Key words: animal welfare, cow-calf separation, citizen values, dairy production, animal care

\section{INTRODUCTION}

Public interest in, and concern for, the treatment and welfare of production animals appears to be growing, or is at least becoming more visible (Verbeke, 2009; Alonso et al., 2020). Much of this concern centers on contentious practices and the call for more socially sustainable management practices (Vermeir and Verbeke, 2006; Boogaard et al., 2008). Of particular concern in the dairy industry is calf management, including early separation of cows and calves (Placzek et al., 2021; Hötzel et al., 2017) and the practice of individual housing of the calves after removal from the dam (reviewed by Costa et al., 2016).

In most dairy production systems cows are separated from their calves within a few hours of birth (reviewed by Beaver et al., 2019), causing acute distress responses (Newberry and Swanson, 2008) and preventing cows from performing and calves from receiving natural maternal behaviors (Flower and Weary, 2003). There is also some evidence that separation poses additional welfare concerns for both cows and calves; for the calf this includes reduced growth (Krohn et al., 1999), impaired development of social behaviors (Wagner et al., 2012; Buchli et al., 2017), and performance of stereotypic behaviors (Roth et al., 2009), and for the cow increased risk of mastitis (Mdegela et al., 2004).

From a management perspective, early separation can improve ease of handling animals in modern facilities and the sale of more milk (Flower and Weary, 2003) and when done soon after birth reduces vocalizations and other signs of acute separation distress compared with later separation (e.g., Stěhulová et al., 2008). As reported by Ventura et al. (2013) and Pempek et al. (2017), some proponents of early separation argue that this practice protects calves from exposure to patho- 
gens. However, a recent systematic review of the available evidence concludes that hygiene practices (e.g., maintaining a clean calving and barn environment) play a greater role in determining pathogen risk than cow-calf contact itself (Beaver et al., 2019).

Globally it is still common to separate cows and calves within a few hours of birth, and in many parts of the world the calves are individually housed (e.g., Brazil, Hötzel et al., 2014; United States, USDA, 2016; Canada, Winder et al., 2018). An alternative practice to individual housing is to socially house the calves in groups of 2 or more (Cantor et al., 2019); a practice believed by many working within the dairy industry to address some public concerns around social isolation (Ventura et al., 2013; Widmar et al., 2017; Perttu et al., 2020).

Some, however, argue that socially housing calves fails to address concerns regarding the removal of the cow (Roth et al., 2009). One alternative to keeping cow and her calf together is the foster cow system, where calves are still removed from the mother at birth but are then fostered (usually with 2 or 3 other calves) by another lactating cow (described by Hudson, 1977; Vaarst et al., 2001). There has been some work done on foster cow systems, but this work has focused on calf growth, maternal behavior, and the cow-calf bond (see Kent, 2020) and not whether the system itself is viewed as acceptable by the public.

Previous studies have revealed public opposition toward early cow-calf separation (in North America, Ventura et al., 2013, 2016; Germany and United States, Busch et al., 2017; Brazil, Hötzel et al., 2017; the Netherlands and Norway, Boogaard et al., 2010). However, with the exception of recent work solely comparing perceptions of individually housed versus group housed calves (Perttu et al., 2020), we are not aware of any studies that have examined perceptions of alternative cow-calf management systems. When investigating socially sustainable systems it follows that an important consideration is understanding public attitudes toward specific systems (Vermeir and Verbeke, 2006; Verbeke, 2009); industry led alternatives may not necessarily resonate with societal values and there is risk that a particular system may be rejected once awareness grows among the public.

The primary aim of this study was to investigate participants' attitudes toward the management of cows and calves in cow-calf management systems that differ in the type of social and maternal contact. On the basis of previous research, we predicted that attitudes would be most favorable toward the management system that allowed continued cow-calf contact and least favorable to early separation followed by individual housing, but we did not have clear basis for predicting attitudes to- ward the separated and kept with a foster cow system and the separated and group housed system. We also describe the considerations and concerns of participants regarding these different cow-calf management systems and how these influenced their attitudes.

\section{MATERIALS AND METHODS}

We conducted an online survey (see Supplemental Material S1; https://doi.org/10.5683/SP3/GQ8DUY) using 2 samples of participants which were later combined into 1 data set. The first sample included Canadian residents 18 yr of age and older on Amazon's Mechanical Turk (MTurk) platform. The second sample included American residents $18 \mathrm{yr}$ of age and older recruited by Amazon's CloudResearch Prime Panels service. This study was approved by the Behavioral Research Ethics Board at The University of British Columbia, Canada (H19-02016). All participants consented to the study after reading a brief description of the topic of the survey and were informed that data would be collected and treated anonymously. Canadian participants who completed the survey on the MTurk platform received $\$ 2$ CAD in compensation. American participants were compensated by CloudResearch. CloudResearch uses a varied compensation scheme (e.g., gift card, reward points), but gave an estimate of providing the equivalent of $\$ 1$ to $\$ 2$ USD per participant in compensation.

\section{Survey Design}

Participants were given a brief statement to read introducing the topic of cow-calf management in the dairy industry and asking for their views: "To produce milk, cows must give birth to a calf approximately once a year. We wish to hear your views regarding the methods used to manage (i.e., house and care for) cows and calves." Each participant was then randomly assigned to 1 of 4 cow-calf management systems that differed in when cows and calves were separated and in the type of social contact provided (see Table 1).

Following Cardoso et al. (2018), participants were then asked to respond to 3 questions, all on a 7-point semantic differential scale (Friborg et al., 2006) and designed to assess attitudes toward the scenario (see Ajzen and Fishbein, 2000): (1) "How much do you disagree/agree with the use of this system for managing cows and calves?" $(1=$ strongly disagree to $7=$ strongly agree); (2) "How inappropriate/appropriate do you consider this system for managing cows and calves?" (1 $=$ completely inappropriate to $7=$ completely appropriate); and (3) "How unacceptable/acceptable do you consider this system for managing cows and calves?" (1 $=$ totally unacceptable to $7=$ totally acceptable). A 
score of 4 was neutral on all scales (e.g., neither unacceptable nor acceptable). As quantitative questions can be limiting (Johnson and Onwuegbuzie, 2004; Guest et al., 2014), we provided participants the opportunity to expand on their answers with an open-ended question asking participants, "Please explain your views about this cow-calf management system."

To investigate if and how participants factored in the perceived quality of life of the animals in their judgment of the system, participants were asked to rate how relevant their considerations of the quality of life of each of the animals (cows and calves in all systems; and cows, calves, and foster cows in the separated and kept with foster cow system) were in determining their views regarding the cow-calf management system. Answers were on a semantic differential scale of $1=$ not at all relevant to $6=$ extremely relevant.

Participants were then asked to evaluate the perceived quality of life of animals in the cow-calf management system on a semantic differential scale of $1=$ very bad to $7=$ very good, again with 4 being neutral at neither good nor bad. No definition of quality of life was given to allow participants space to approach this question with their own conceptions. As a result of high internal consistency and unidimensionality during data analysis, participants' responses to this latter question (i.e., their perceptions of quality of life) were later collapsed into the construct perception of animal welfare along with participants' responses to the questions about individual aspects of animal welfare asked in the next section and described below.

The next section of the survey investigated potential reasons for participants' attitudes toward the system based on the 3-sphere animal welfare conception proposed by Fraser et al. (1997), again following Cardoso et al. (2018); participants were asked to describe the health, feelings, and ability to live a natural life, of the cows and the calves (and the foster cows in the separated and kept with foster cow system only) in the cowcalf management system. In addition, we asked how participants perceived the standard of care provided to animals in this system, as discussed by Weary and Robbins (2019). Answer choices in this section were on a semantic differential scale of 1 to 7 , with $1=$ very negative perception (e.g., "very unhealthy" for the health question, or "very bad" for the feelings question) and $7=$ very positive perception (e.g., "very unhealthy" for the health question, or "very good" for the feelings question), and 4 being a neutral midpoint (e.g., "neither unhealthy nor healthy" for the health question, or "neither bad nor good" for the feelings question,).

Given that the different scenarios all referred to the farmer milking the cow we also asked participants to describe their willingness to pay (WTP) for milk from their given cow-calf management system in comparison to how much they currently pay for milk (i.e., not be willing to pay as much = WTP less; willing to pay about the same $=$ WTP same; willing to pay more = WTP more). Lastly, participants were asked sociodemographic questions (age, gender, level of education, rural versus urban or suburban residence, income, presence of children, presence of pets, self-defined familiarity with the dairy industry $(1=$ not at all familiar to 6 $=$ extremely familiar), if they were involved or not with the dairy industry, and if they consumed dairy).

\section{Participant Recruitment and Selection}

The survey was developed in Qualtrics (www.qualtrics .com). It was first released to a convenience sample (i.e., there were no predefined quotas set to ensure participant representation across certain socio-demographic levels) of Canadian residents $18 \mathrm{yr}$ of age and older on the MTurk platform from September 26, 2019, to

Table 1. Text given to participants for each experimental condition describing a cow-calf management system differing with respect to whether the calf was separated from the mother cow and the type of social contact provided following separation

\begin{tabular}{ll}
\hline Group & Description \\
\hline Separated and individually housed & $\begin{array}{l}\text { Dairy cows must give birth to a calf to produce milk. Within a few hours after birth the calf is } \\
\text { separated from the cow. The cow is then housed with other cows and milked by the farmer. The calf } \\
\text { is individually housed by itself and is fed milk by the farmer. }\end{array}$
\end{tabular}

Separated and group housed

Separated and kept with foster cow

Not separated and group housed
Dairy cows must give birth to a calf to produce milk. Within a few hours after birth the calf is separated from the cow. The cow is then housed with other cows and milked by the farmer. The calf is housed with other calves and is fed milk by the farmer.

Dairy cows must give birth to a calf to produce milk. Within a few hours after birth the calf is separated from the cow. The cow is then housed with other cows and milked by the farmer. The calf is housed with other calves and with unrelated 'foster' cows from which the calves are able to nurse.

Dairy cows must give birth to a calf to produce milk. Within a few hours after birth the calf is not separated from the cow. The cow and calf are housed together as a pair with other cow-calf pairs. The cow is milked by the farmer, but the calf is also able to nurse from its mother cow. 
October 6, 2019. After preliminary analysis of the data from this Canadian sample, the survey was released to a representative sample of American residents (following participant quotas based on US (2018) census data for gender, age, region, education, and income) $18 \mathrm{yr}$ of age and older through the Prime Panels service from February 28, 2020, to March 15, 2020.

A total of 461 Canadians responded to the survey on MTurk. Following the removal of 154 participants who either failed the attention check (an institutional manipulation check adapted from Oppenheimer et al., 2009) or supplied duplicate responses (submitted multiple surveys), 307 Canadian responses were retained for further analysis in the combined data set. A total of 2,536 Americans responded to the survey on Prime Panels. Following the same attention check and quality control procedure as for the Canadian sample, 1,049 of these participants were removed. This left 1,487 American responses to be added to the Canadian responses in the combined data set (see Supplemental Material S2 for the cleaned data set; https://doi.org/10.5683/SP3/ GQ8DUY) for a total of 1,794 participants.

As the Canadian sample was a convenience sample without predefined participant quotas, we provide a breakdown of the socio-demographics of our Canadian participants in comparison to Canadian census averages from 2016 (Statistics Canada, 2017) in Table 2. Canadian participants were on average younger (average age of $32.8 \mathrm{yr}$ vs. Canadian average age of $41 \mathrm{yr}$ ), more likely to not identify as female, and more likely to have attained a higher level of education compared with Canadian census averages. It is also important to note that although the American sample was recruited as a representative sample based on predefined census quotas for gender, age, region, education, and income, these quotas only select for a subset of socio-demographic categories as defined in the 2018 US census, and some socio-demographics were over or under-represented in our analysis following data cleaning. Despite these limitations, we believe that both the Canadian and American samples are useful in investigating a range of views on cow-calf management systems. Results are provided and discussed for a combined data set as opposed to for each country's sample separately. This was done to investigate the strength of our results across participants from different samples in different countries. Ultimately, no effects of either country sample nor an interaction between country sample and cow-calf management system were found in preliminary models. Socio-demographics of the combined data set are provided in Table 3.

Crowdsourcing platforms such as Amazon's MTurk are commonly used in perception research and considered to be relatively reliable and cost-effective in com- parison to more traditional face or telephone surveying methods (Woods et al., 2015; Lutz, 2016). There is also some work in support of the benefits of and the reliability of representative samples from services such as Prime Panels once participants pass a screening test or attention check (Chandler et al., 2019).

\section{Data Analysis}

Quantitative Data. The data were analyzed using SAS (version 9.4, SAS Institute Inc.; see Supplemental Material S3 for the code file; https://doi.org/10.5683/ SP3/GQ8DUY). Data visualization for Figure 1 and Figure 2 was performed using R 3.5.1 (R Core Team, 2018; R Studio Team, 2016) and the ggplot2 package (Wickham, 2016). Of the 1,794 participants included in the quantitative analysis, 419 participants received the separated and individually housed system, 429 received the separated and group housed system, 469 received the separated and kept with foster cow system, and 477 received the not separated and group housed system.

Internal consistency reliability of related questions was assessed using Cronbach's a (Ellis, 2016). Participants were highly consistent (Cronbach $\alpha=0.91$ ) in their rating of how relevant their considerations of the quality of life of cows and of calves were in determining their views regarding the cow-calf management system, so the relevance scores for cows and for calves were averaged. Participants were highly consistent (Cronbach's $\alpha$ of 0.97 ) in their responses to the 3 attitude questions asking how much they agreed with the cow-calf management system described, how appropriate they considered it, and how acceptable they considered it for managing cows and calves. Additionally, we assessed the unidimensionality of these attitude aspects using principal factor analysis (Bartholomew et al., 2011). Here, unidimensionality was pronounced with an eigenvalue of the first factor being 2.66, remaining factors being negative and communality values $>0.8$ (SlocumGori and Zumbo, 2011; Ellis, 2016). Thus, individual responses to these questions were averaged to create a construct of a mean attitude score for each participant.

Participants were also highly consistent (Cronbach's $\alpha$ of 0.97 ) in how they responded to questions about each individual animal welfare aspect (health, feelings, ability to perform natural behaviors, standard of care provided) and to the question asking them to describe quality of life as applied to both cows and to calves in the described management systems. Here unidimensionality was also confirmed. The first retained factor had an eigenvalue of 7.90 whereas all remaining factors had eigenvalues of $<0.43$, which together with communality values of $>0.8$ confirmed unidimensionality of the data set (Slocum-Gori and Zumbo, 2011; Ellis, 
2016). As a result of this high internal consistency reliability and unidimensionality, perceptions of each individual aspect of animal welfare and of quality of life for both cows and for calves were collapsed into a single construct representing perception of animal welfare. The relationship between participants' perceptions of animal welfare within that system and participants' attitudes toward their given cow-calf management system was tested with Pearson correlation.

General linear models were created for each construct as a dependent measure (attitude and perception of animal welfare). Preliminary models tested the effects of cow-calf management system; socio-demographic factors such as country (binary: Canada or US), age (continuous), gender [treated as binary: identifies as female or does not identify as female (i.e., male or prefers not to say)], level of education (treated as continuous), residence [binary: rural or not rural (i.e., urban or suburban)], income (treated as continuous), presence of children (binary: yes or no), presence of pets (binary: yes or no), familiarity with the dairy industry (treated as continuous), and dairy consump- tion (binary: yes or no); and the interactions between each of the socio-demographic variables and cow-calf management system. Type III sum of squares and Tukey-Kramer adjustments for pairwise comparisons were used for all models. Socio-demographic variables of country, income, presence of children, presence of pets, and all the interactions between socio-demographic variables (except for those of the interactions between gender and cow-calf management system and between familiarity with the dairy industry and cow-calf management system) exceeded $P>0.05$ in preliminary models. Therefore, these variables and interactions were excluded from the final models. Level of education was also excluded from the final model for attitude (but not from the final model for perception of animal welfare) as a result of exceeding $P>0.05$ in the preliminary model for attitude (but not in the preliminary model of perception of animal welfare). In the following results and discussion section, slopes, and standard errors (SE) are presented for continuous variables with $P \leq 0.05$. Least squares means (also known as estimated marginal means; Searle et al., 1980) and

Table 2. Number and percentage of Canadian participants $(\mathrm{n}=307)$ sorted by socio-demographics and presented in relation to the 2016 Canadian census averages for the population (Statistics Canada, 2017)

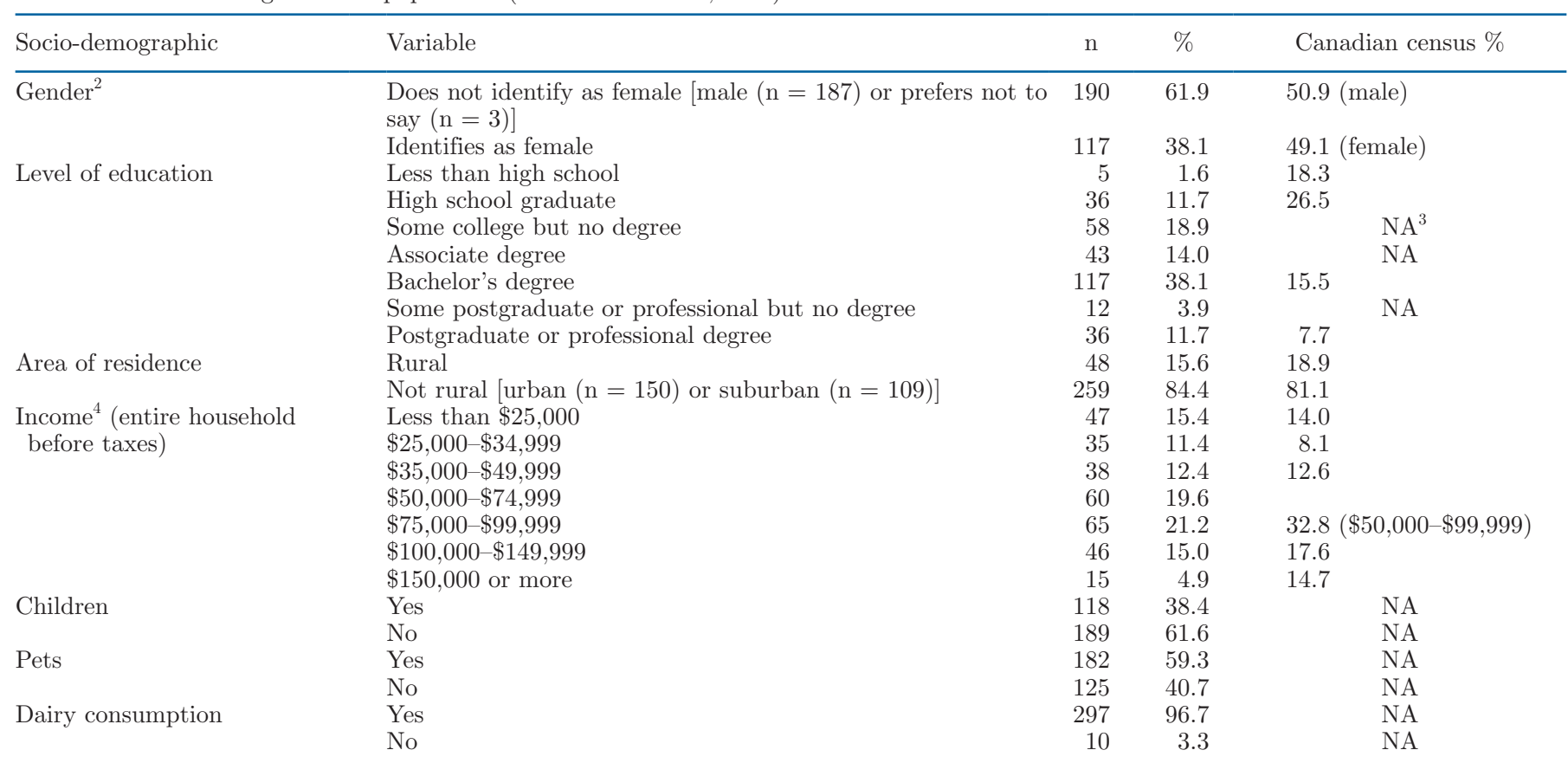

${ }^{1}$ Area of residence census data are from 2011 (Statistics Canada, 2011).

${ }^{2}$ For the purposes of this study we treated gender as a binary variable by presenting the number of our participants who selected "female" for gender as "identifies as female" and the combined number of our participants who selected "male" or "prefer not to say" as "does not identify as female." Statistics Canada (2017) reports gender only as male or female. We present our results for gender in relation to census averages by comparing the value of "identifies as female" in our study to the value of "female" in the census report. We present numbers for the value "does not identify as female" next to the census numbers for the value "male," but recognize that gender is not truly binary and our value of "does not identify as female" also included participants who preferred not to say which gender they identified with.

${ }^{3} \mathrm{NA}=$ not applicable in Canadian census as not reported on in the census performed by Statistics Canada (2017).

${ }^{4}$ For income, $\mathrm{n}=306$ as a result of 1 missing value. 
SE are presented from these models below for categorical variables with $P \leq 0.05$. For the calculation of least squares means, the coefficients of categorical variables were set to be proportional to those found in the data set to better reflect the sample population being modeled. Additionally, the least squares means for the effects of cow-calf management system and of gender were computed using separate margins for each level of these effects to make them estimable in both the model of attitude and the model of perception of animal welfare. The resulting least squares means for cow-calf management system and for gender were equivalent to the raw means in this case.

The effect of cow-calf management system on participants' WTP for milk from their given cow-calf management system in comparison to what they currently pay for milk was assessed using logistic regression. As the WTP question asked participants about potential changes in their buying behavior in response to a specific system, only participants $(\mathrm{n}=1,326$ out of 1,794 total participants) who answered that they (1) bought milk and (2) believed that the cow-calf management system described was not completely similar to how they thought cows and calves are currently managed to produce the milk they normally buy were included in the analysis of WTP data. We used a binary logit model ( $\mathrm{n}=1,311$ after further exclusion from the model of participants missing socio-demographic values) with Fisher's scoring method and maximum likelihood estimation to model the effects of the cow-calf management system, country, and socio-demographic factors (i.e., country, age, gender, level of education, residence, income, presence of children, presence of pets, and familiarity with the dairy industry) on participants' WTP. The groups WTP same and WTP more were combined into a single event (WTP same or more) to be modeled, signifying willingness to pay either the same or more for milk from the given cow-calf management system. This event was compared with WTP less. Given the predicted effects of socio-demographic factors on WTP for farm animal welfare (see review by Clark et al., 2017), all socio-demographic effects were kept in the final model, in addition to the treatment effect of cow-calf management system, regardless of $P$-values in preliminary models. However, to better focus on main effects of treatment and socio-demographic variables, all the interactions between socio-demographic variables and cow-calf management system were excluded from the final model after each exceeded $P>0.05$ in preliminary models. Lyford et al., (2010) followed a similar approach of excluding interaction effects with $P>0.05$ in preliminary models when investigating effects of consumer demographics and meat consumption preferences on consumer's WTP for beef quality. Tackie et al., (2015) also did not include interaction effects in their logistic regression models assessing the effects of socioeconomic factors and meat attributes on WTP for meat products. The estimated parameters (log-odds

Table 3. Number and percentage of participants $(n=1,794)$ sorted by socio-demographics; there were 307 Canadian participants and 1,487 American participants

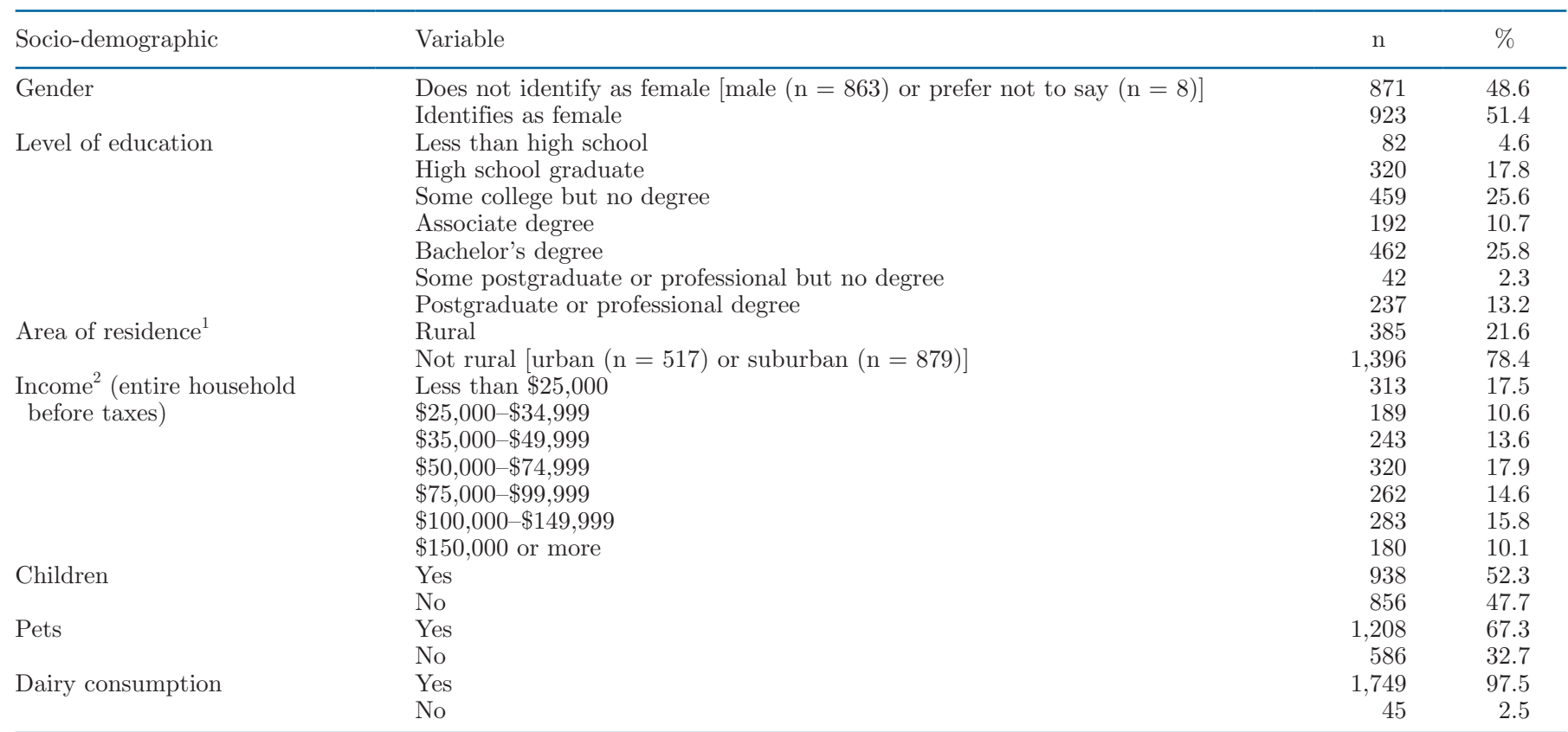

${ }^{1}$ For area of residence, $\mathrm{n}=1,790$ as a result of 4 missing values. Statistics for models incorporating this variable were adjusted accordingly.

${ }^{2}$ For income, $\mathrm{n}=1,781$ as a result of 13 missing values. Statistics for models incorporating this variable were adjusted accordingly. 


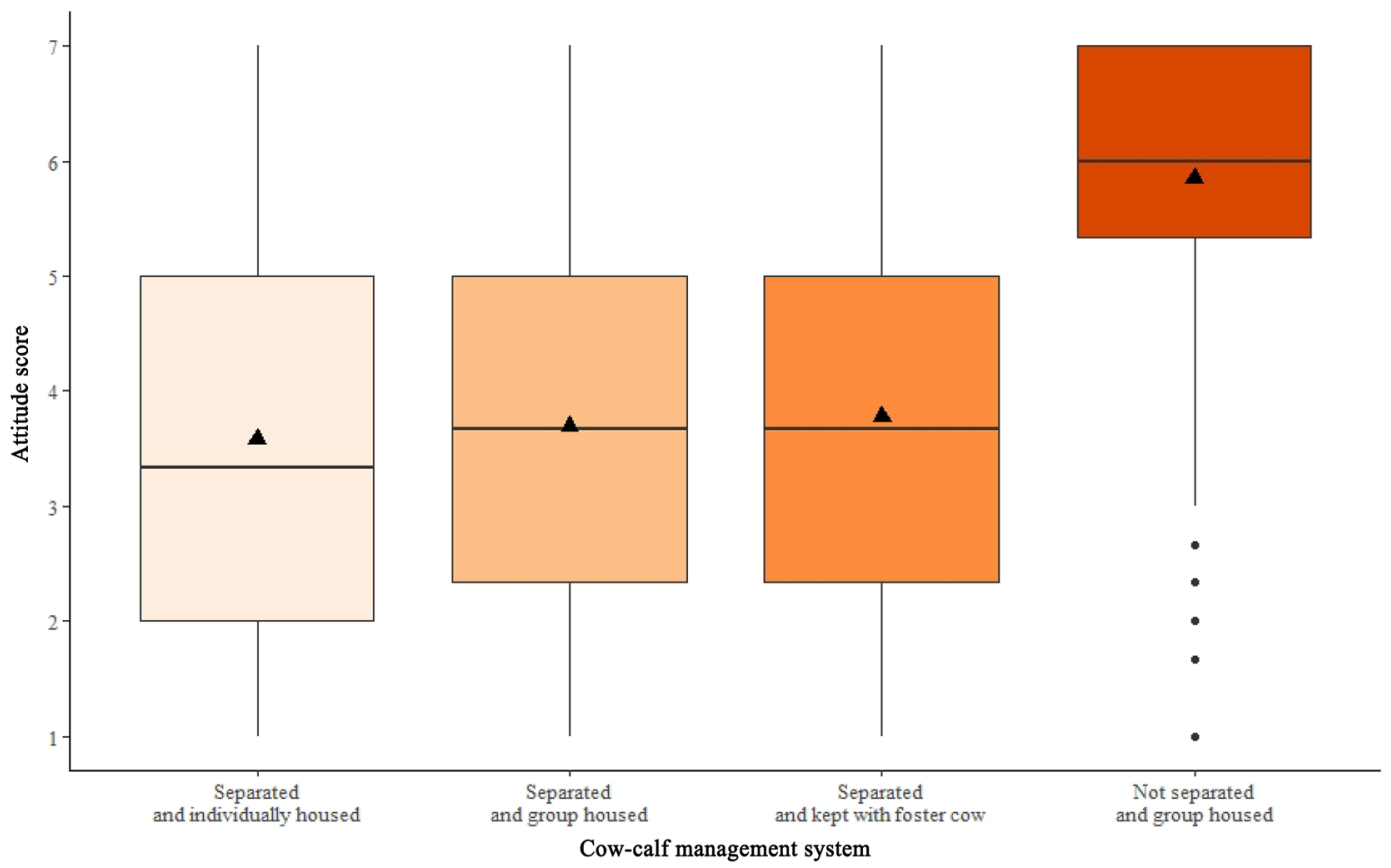

Figure 1. Participant $(\mathrm{n}=1,794)$ attitude scores toward different cow-calf management systems. Each participant was randomly assigned to 1 of 4 scenarios that each described a different cow-calf management system. Attitude was a construct consisting of the average of 3 semantic differential scale (1-7) questions, where a score of 4 indicates a neutral attitude, scores of less than 4 indicate a more negative attitude, and scores of greater than 4 indicate a more positive attitude toward the cow-calf management system. The central triangle shape point in the boxplot represents the mean, the central line represents the median, and the limits of the boxes represent the 25th and 75th percentiles (the first and third quartiles). The vertical lines extending below and above the box (the lower and upper whiskers) represent the smallest observation greater than or equal to the 25 th percentile minus 1.5 times the interquartile range and the largest observation less than or equal to the 75 th percentile plus 1.5 times the interquartile range, respectively. The circular points beyond the vertical lines represent outliers.

regression coefficients), SE, Wald Chi-squared values, and $P$-values for all variables in the final model with $P \leq 0.05$ are presented in the following results and discussion section.

Planned contrasts between each of the 4 different cow-calf management systems were performed to estimate odds ratios of participants' WTP same or more for milk (compared with what participants' currently pay) when given different systems. These odds ratio estimates along with $99 \%$ Wald confidence limits are presented. The $99 \%$ Wald confidence limits $(\alpha=0.01)$ were used here to adjust for multiple $(\mathrm{n}=6)$ planned comparisons.

Qualitative Data. We used generic qualitative inquiry in our mixed methods approach toward the qualitative data. Generic qualitative inquiry, as described by Percy et al. (2015; page 78), "investigates people's reports of their subjective opinions, attitudes, beliefs, or reflections on their experiences, of things in the outer world" and is particularly useful for mixed methods studies. Within this framework we used thematic analysis (Miles et al., 2014; Percy et al., 2015) to analyze the qualitative data. During this process we used an iterative coding process to identify themes and subthemes expressed in participants' free responses.
This iterative coding process combined a priori codes determined from the existing literature with a set of codes discovered through inductive coding of the qualitative data from the first sample of 307 Canadian participants that fit within the existing codes (Miles et al., 2014; Onwuegbuzie and Combs, 2015). The resulting codebook was then applied to the larger, second sample of 1,487 American participants. It is also important to note our position, specifically as animal welfare researchers, our close links with the dairy industry and our association with the UBC dairy farm; our research process, coding, and interpretation of the results were likely influenced by these factors (Walker et al., 2013; Berger, 2015).

For the a priori coding we focused our approach using the theoretical framework from Fraser et al. (1997), which defines animal welfare as consisting of biological functioning and health; affective states; and naturalness, including the ability of animals to express natural behaviors. The other a priori codes were derived from themes identified in previous cow-calf perception work, such as calf nutrition, separation, separation distress, cow-calf relationship (or bond), dissatisfaction with motivations, change, milk production (Ventura et al., 2013; Busch et al., 2017; Hötzel et al., 2017). During the 
iterative phase any a priori themes that were expressed by our participants were confirmed in the codebook. We were also open to any new themes that emerged, which were then added to the codebook through open coding. Codes and themes were repeatedly discussed among the research team during the coding process. The resulting codebook was checked for consistency and finalized by having 2 researchers (Sirovica and Ritter) coding answers from randomized subsamples of the Canadian responses. Differences in coding were discussed, resolved, and used to update the codebook before the final codebook was used by both researchers to code a final subsample of responses. Intercoder reliability was assessed at this stage using NVivo (QSR International Pty Ltd., version 12; https://www.qsrinternational .com/nvivo-qualitative-data-analysis-software/home). The Cohen's kappa coefficient was 0.65, suggesting substantial agreement between coders (Landis and Koch, 1977). One researcher (Sirovica) then coded all the Canadian responses with the finalized codebook. For the American sample the same procedure to assess intercoder reliability using the same finalized codebook was followed (as no new codes were identified during this phase with a subsample of the American responses), this time between researchers Sirovica and Hendricks. The Cohen's kappa coefficient in this case was 0.68, again suggesting substantial agreement between coders (Landis and Koch, 1977). Hendricks then coded all the American responses.

Results are presented by theme as opposed to by treatment. Researchers were not blinded to treatment so that they had full context for qualitative analysis of the short free responses (i.e., some participants would refer heavily to, but not name, the cow-calf management system described, making knowing the specific management system those participants were provided important to the analysis). Results include discussion of how participants of different attitude valences brought up similar themes and the different integration of these themes and subthemes by participants. We focus on the range and integration of themes presented by participants as opposed to the quantity.

Unique and anonymous identifiers [i.e., the country abbreviation (CA for Canadian participants and US for American participants) followed by a random number from 1 to 1,487 for American participants and from 1 to 307 for Canadian participants] were assigned to each participant and used to label quotes presented in this

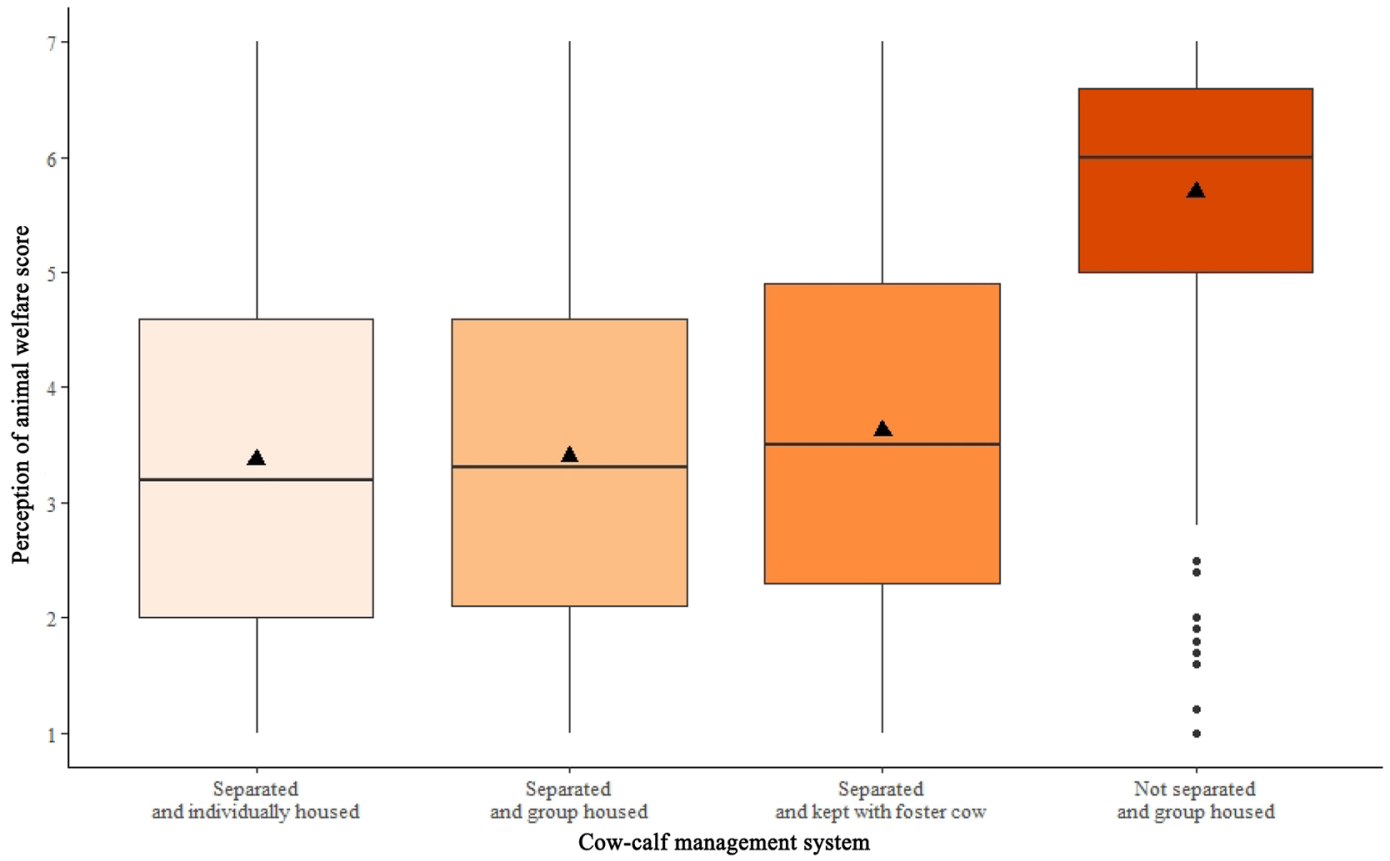

Figure 2. Participant $(\mathrm{n}=1,794)$ perceptions of animal welfare of cows and calves in 4 different cow-calf management systems. Each participant was randomly assigned to 1 of 4 scenarios that each described a different cow-calf management system. Perception of animal welfare was a construct consisting of the average of 10 Semantic differential scale (1-7) questions asking about both cows' and calves' quality of life, health, feelings, abilities to live natural lives, and standard of care. A score of 4 indicates a neutral perception, scores of less than 4 indicate a more negative perception, and scores of greater than 4 indicate a more positive perception. The central triangle shape point in the boxplot represents the mean, the central line represents the median, and the limits of the boxes represent the 25th and 75th percentiles (the first and third quartiles). The vertical lines extending below and above the box (the lower and upper whiskers) represent the smallest observation greater than or equal to the 25th percentile minus 1.5 times the interquartile range and the largest observation less than or equal to the 75 th percentile plus 1.5 times the interquartile range, respectively. The circular points beyond the vertical lines represent outliers. 
paper (e.g., US97 or CA3). Each quote was also labeled with the system (separated and individually housed, separated and group housed, separated and kept with foster cow, or not separated and group housed system). Any explanatory information to maintain meaning of quotes or use of an ellipsis to shorten quotes were presented in square brackets (e.g., [...]) within the quotes. Minor spelling errors within quotes were edited for presentation unless such edits would change the meaning of quotes. All responses associated with each unique and anonymous identifier can be viewed in Supplemental Material S4 (https://doi.org/10.5683/SP3/GQ8DUY).

\section{RESULTS AND DISCUSSION}

\section{Quantitative Findings}

Attitude Toward System. Participant attitudes varied between different cow-calf management systems (Figure 1). Participants had a more positive attitude toward the not separated and group housed system (means \pm SE; $5.8 \pm 0.07$ ) compared with the separated and individually housed $(3.6 \pm 0.07)$, separated and group housed $(3.7 \pm 0.07)$, and separated and kept with foster cow systems $\left(3.8 \pm 0.07 ; F_{3,1766}=54.63\right.$; $P<0.0001)$. There were no differences between attitudes between the separated and individually housed, separated and group housed, and separated and kept with foster cow systems, all of which employed early separation of original cow-calf pairs.

Although there was no difference in attitude between the 3 systems all involving early cow-calf separation, there was an interaction between system and gender $\left(F_{3,1766}=8.68 ; P<0.0001\right)$ resulting from participants who identified as female having more negative attitudes to the 3 systems involving early separation. For example, participants who identified as female had lower attitude scores toward the separated and individually housed system $(3.2 \pm 0.11)$ than participants who did not identify as female had toward either the separated and individually housed system $(4.0 \pm 0.10)$, the separated and group housed system $(4.0 \pm 0.11)$, or the separated and kept with foster cow system (4.1 $\pm 0.10)$. Within the not separated and group housed system there was no difference in attitudes between participants who identified as female and participants who did not. Overall, participants who identified as female had lower attitudes toward their given system $(4.0 \pm 0.05)$ than those who did not identify as female $\left(4.5 \pm 0.05 ; F_{1,1766}=41.24 ; P<0.0001\right)$. This was not surprising, given that women generally express more concern over animal management practices than men do (McKendree et al., 2014), with Ventura et al. (2013) finding that women showed less support for the specific practice of early separation than men did. Thus, the overall result of attitudes toward system being higher in participants given the not separated and group housed system compared with each of the systems involving early separation remained consistent, even with these gender effects.

Ventura et al. (2013) reported that respondents less familiar with the dairy industry showed less support for early cow-calf separation than respondents directly involved (i.e., veterinarians and farmers) with the industry or respondents who self-reported being very familiar with dairy production. This lower support for early separation among people less familiar with the dairy industry could explain why attitudes were lower among our participants with less experience with the dairy industry, as illustrated by a positive slope of $0.25( \pm 0.06)$ between industry familiarity and attitude $\left(F_{1,1766}=72.78 ; P<0.0001\right)$. There was also an interaction between system and industry familiarity $\left(F_{3,1766}=\right.$ 3.91; $P=0.009)$. However, support for the not separated and group housed system was higher than that for the other systems regardless of industry familiarity.

A slightly more positive attitude toward each system, including those systems involving early separation, was also expressed by participants who reportedly lived in rural locations $(4.5 \pm 0.08)$ compared with urban or suburban locations $\left(4.2 \pm 0.04 ; F_{1,1766}=6.92 ; P=\right.$ 0.009 ). This is consistent with the findings of Perttu et al. (2020) that rural residents who responded to their study on perceptions of dairy calf housing were more accepting toward individual calf housing than urban residents were.

Age was positively associated with attitude; for every decade increase in participant age, attitude increased by $0.11( \pm 0.02)$ on the semantic differential scale $\left(F_{1,1766}=\right.$ 25.85; $P<0.0001)$. Older participants thus appeared to have less negative attitudes toward their given management system. Similarly, Boogaard et al. (2011) found in their national Dutch survey that older participants (specifically, those older than 65) were more satisfied with contemporary (i.e., conventional, rather than more "natural" alternatives such as keeping cows and calves together) dairy farming and management methods.

Dairy consumption $\left(F_{1,1766}=72.92 ; P<0.0001\right)$ was also associated with attitude, with no consumption of dairy products being associated with lower attitude scores $(2.4 \pm 0.23)$ compared with the attitude scores $(4.3 \pm 0.04)$ of people who consume dairy. Although only $2.5 \%$ of participants in this study reported not consuming dairy products, it is not surprising that some participants with negative attitudes toward the system were less likely to drink milk (or vice versa); attitudes are expected to be predictive of behavior (Vaske, 2008). Importantly, despite the much lower attitudes 
toward any management system of participants who did not consume dairy compared with the attitudes of participants who did consume dairy, the overall result of attitudes being relatively lower toward all systems involving early cow-calf separation compared with a system involving no separation was consistent across both types of participants. This result suggests that management systems involving no separation may even provide a more favorable option to people who already have a negative attitude toward dairy.

Collectively these results support our primary prediction that attitudes would be most favorable toward prolonged cow-calf contact, but show no evidence of increased support for alternatives thought to provide benefits over the standard system of early separation and individual housing. Instead, we found that attitudes were unfavorable toward all systems involving early separation from the mother, regardless of what form of additional social contact was provided.

Previous work has shown evidence of public concern for the ability of all dairy animals to interact socially (Widmar et al., 2017) and for calves to be housed together (Perttu et al., 2020), so it is perhaps surprising that the alternate management systems that allowed for social contact (either with foster cows or other calves) failed to elicit more favorable attitudes. We suggest that the participants did not view these alternate forms of social contact as adequate replacements for social contact from the mother.

In studies where participants were only given a choice between individually housed calves and group housed calves (e.g., Perttu et al., 2020), participants had to choose between the 2 systems (essentially forcing the participants to trade off attributes of one system over the other). Work by Ryan et al. (2015) indicated that citizens asked to choose between gestation stalls, group housing for sows, or another system that was not described chose the other system; suggesting that they found both options unsatisfactory. In the current study, participants were not asked to choose, but rather presented with just a single option. More work is required to understand how these methodological considerations may affect responses.

Perception of Animal Welfare Within Systems. Participant perceptions of animal welfare also varied between different cow-calf management systems (Figure 2). Similar to their attitudes toward the system, participants had a more positive perception of animal welfare within the not separated and group housed system $(5.7 \pm 0.07)$ compared with those that received the separated and individually housed $(3.4 \pm 0.07)$, separated and group housed $(3.4 \pm 0.07)$, and separated and kept with foster cow systems $\left(3.6 \pm 0.07 ; F_{3,1765}\right.$ $=54.19 ; P<0.0001)$. There were again no differences between perceptions of animal welfare within the latter 3 systems, all of which employed early separation of original cow-calf pairs.

As with the model of participant attitudes, although there were no main system effect differences on perceptions of animal welfare between the 3 systems all involving early cow-calf separation, there was an interaction between system and gender $\left(F_{3,1765}=6.64 ; P\right.$ $=0.0002)$ due to participants who identified as female having more negative perceptions of animal welfare to the 3 systems involving early separation. For example, participants who identified as female had lower perceptions toward the separated and individually housed system $(3.2 \pm 0.10)$ than participants who did not identify as female had toward either the separated and individually housed system $(3.7 \pm 0.10)$, the separated and group housed system $(3.6 \pm 0.10)$, or the separated and kept with a foster cow system $(3.7 \pm 0.10)$. However, in response to the not separated and group housed system, there were no differences in perceptions of animal welfare between participants who identified as female and participants who did not. Overall, participants who identified as female had lower perceptions of animal welfare $(3.9 \pm 0.05)$ than those who did not identify as female $\left(4.2 \pm 0.05 ; F_{1,1765}=10.37 ; P=\right.$ $0.001)$. This is in line with previous reports of women expressing more concern for animal welfare than men do (Beardsworth et al., 2002; McKendree et al., 2014), which suggests women may be more critical in their perceptions of animal welfare within management systems, in this case, specifically toward systems involving early cow-calf separation.

In addition to the positive association of industry familiarity with attitude, the more familiar participants were with the dairy industry, the less negative their perception of animal welfare, as illustrated by a positive slope of $0.23( \pm 0.05)$ between industry familiarity and perception of animal welfare $\left(F_{1,1765}=123.36 ; P<\right.$ $0.0001)$. This result is consistent with previous reports of individuals involved with livestock expressing less concern for animal management and production practices (Clark et al., 2016). There was also an interaction between system and industry familiarity $\left(F_{3,1765}=4.41\right.$; $P=0.004$ ). However, the overall pattern of perceptions of animal welfare within system being higher in participants given the not separated and group housed system compared with each of the systems involving early separation remained.

Similar to the effects of industry familiarity on concern for and perception of animal welfare, a slightly higher perception of animal welfare among rural residents $(4.2 \pm 0.07)$ compared with urban or suburban residents $(4.0 \pm 0.04)\left(F_{1,1765}=4.90 ; P=0.03\right)$ in our study may be related to a reportedly lower level 
of concern or emphasis placed on farm animal welfare among rural residents. For example, respondents to a survey on perceptions of animal welfare from the Midwest region of the United States (a region with more rural residents) were reportedly less concerned about animal welfare (especially production pig welfare) than respondents from the more urban and suburban Northeast and West regions of the United States (McKendree et al., 2014). Interestingly, the Midwest region of the United States is also more affiliated with pork production practices than other regions of the United States, so McKendree et al. (2014) discussed how respondents from this region may have also had a greater connection and therefore familiarity with pork production. Given the lower concern about animal welfare issues generally reported from individuals more familiar with livestock (Clark et al., 2016), it is not surprising that if many rural residents are more familiar with livestock, they also report lower concern about animal welfare issues.

Age was also positively associated with perception of animal welfare; for every decade increase in participant age, perception of animal welfare increased by $0.17( \pm 0.02)$ on the semantic differential scale $\left(F_{1,1765}\right.$ $=61.22 ; P<0.0001)$. In effect, younger participants tended to have lower perceptions of animal welfare in their given system. These lower perceptions could be a result of younger people tending to express greater concern for animal welfare (McKendree et al., 2014; Alonso et al., 2020).

Also similar to its association with attitude, dairy consumption $\left(F_{1,1765}=87.30 ; P<0.0001\right)$ was associated with perception of animal welfare. No consumption of dairy products was associated with more negative perceptions of animal welfare within a cow-calf management system $(2.1 \pm 0.22)$ compared with the perceptions of animal welfare within system of people who did consume dairy products $(4.1 \pm 0.03)$. Given that perceptions of products and how they are produced can influence consumption habits (Gomez-Corona et al., 2016), it is possible that the poor perceptions of animal welfare within the described management systems from these participants could influence their consumption habits. In fact, there are reports of US consumers reducing dairy consumption due to welfare concerns (McKendree et al., 2012). While animal welfare continues to be a growing concern among consumers, it is one of many considerations (e.g., ethics, health, food quality, taste) consumers have regarding animal products (Beardsworth et al., 2002; Codron et al., 2005; Grunert et al., 2018; Nijland et al., 2018).

Although each of the previously discussed sociodemographics had the same type of effects on both attitude and perception of animal welfare, level of education only affected perception of animal welfare. Level of education had a negative association with participants' perceptions of animal welfare; more educated participants had a more negative perception of animal welfare, as illustrated by a slope of $-0.05( \pm 0.02)$ between level of education and perception of animal welfare $\left(F_{1,1765}\right.$ $=5.06 ; P=0.03)$. This result is consistent with previous reports of an association between education and concern for farm animal welfare (Clark et al., 2016).

Relationship Between Attitude and Perception of Animal Welfare. Among the participants in this study, attitude correlated highly with perception of animal welfare [Pearson's r $(1,794)=0.85 ; P<0.0001$ ]. This positive association suggests that participants' attitudes were associated with their perceptions of the animals' welfare in the system. In addition, many participants $(75 \%)$ rated the quality of life of both cows and of calves as at least "somewhat relevant" in determining their views regarding the cow-calf management system. This evidence is in line with previous work suggesting that there is interest in and concern among consumers and public members on how food animals are treated (e.g., McKendree et al., 2014; de Graaf et al., 2016; Nijland et al., 2018), including dairy cattle welfare (Wolf et al., 2016). However, it is important to note that there are many additional concerns besides animal welfare (e.g., cost, food safety and quality, nutrition, environmental effects) known to contribute to peoples' perceptions of animal products and production systems (e.g., Verbeke, 2009; Miranda-de la Lama et al., 2017). No information nor specific questions targeting these potential additional concerns were provided to participants in this study; the role of these additional concerns requires further investigation.

Willingness to Pay. Responses to the question regarding WTP for milk from the cow-calf management system presented [from participants $(\mathrm{n}=1,326)$ who believed their given system was not "completely similar" to the system they currently bought milk from] varied between the cow-calf management systems. A breakdown of participant responses across the 3 answer choices (i.e., WTP less, WTP the same, or WTP more) is provided in Figure 3. As previously described, WTP same and WTP more were then combined into a single event (WTP same or more) to be modeled. This event was compared with WTP less. In this model, cow-calf management system affected participants' WTP for milk (Wald chi-squared $=102.05 ; P<0.001$ ). The not separated and group housed system had a positive logodds regression coefficient of $2.03 \pm 0.23(P<0.0001)$, suggesting that participants from this system were more likely to be WTP same or more for milk compared with participants from the reference separated and individually housed system. Further analysis of planned contrasts with odds ratio estimates found that participants 


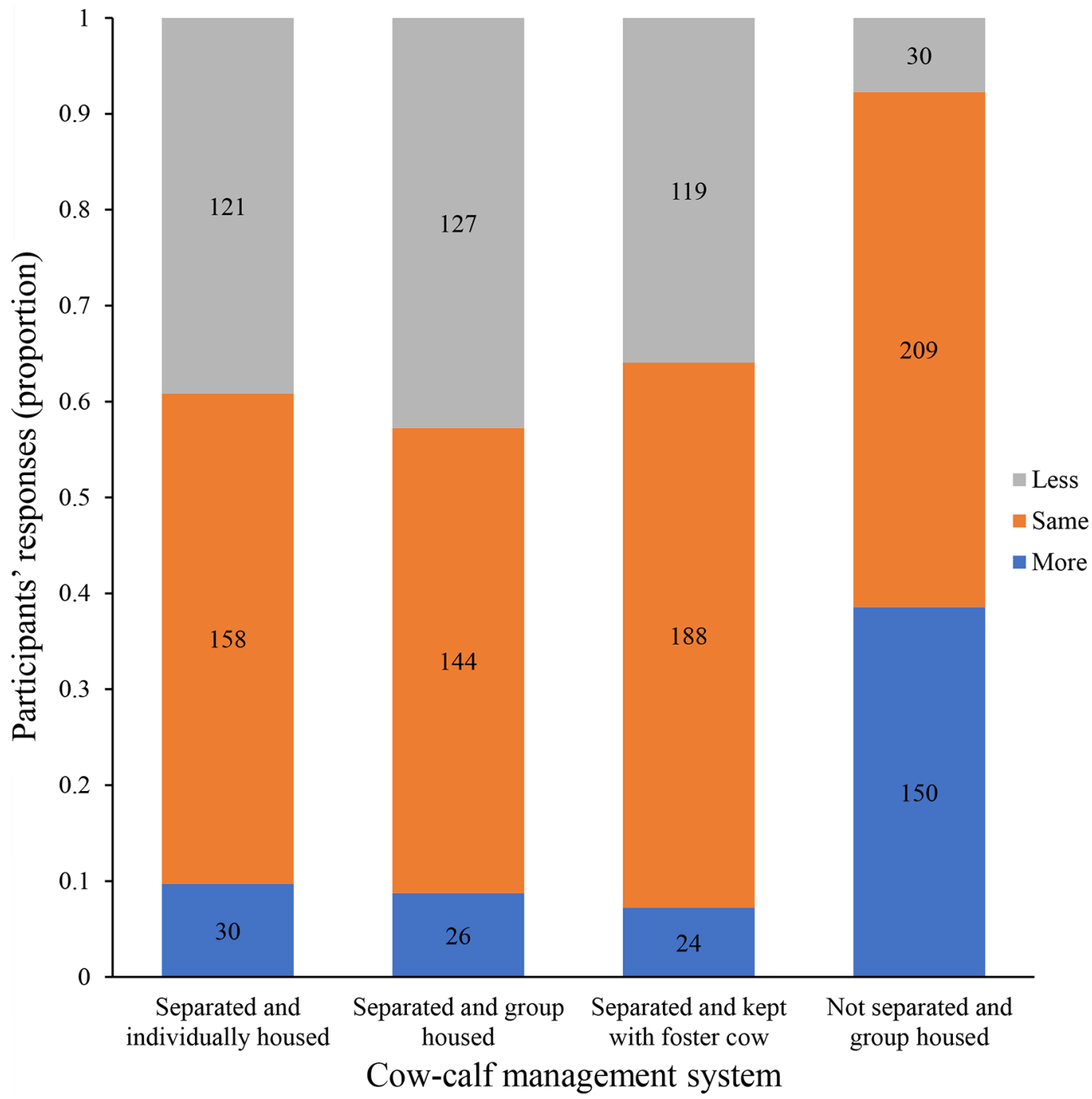

Figure 3. Participant $(\mathrm{n}=1,326)$ responses to a question regarding willingness to pay (WTP; less, the same, or more) for the cow-calf management system presented compared with what they currently pay for milk. Each participant was randomly assigned to 1 of 4 scenarios that each described a different cow-calf management system. The number in each colored section of the bars is the number of participants, whereas the relative height of each colored section of the bars represents the proportion of participants in each treatment group willing to pay less, the same, or more for milk from their given system compared with what they currently pay for milk.

from the not separated and group housed system were 7.61 times more likely to be WTP the same or more for milk compared with what they currently pay than participants from the separated and individually housed system were, 8.65 times more likely to be WTP same or more for milk than participants from the separated and group housed system were, and 6.95 times more likely to be WTP same or more for milk than participants from the separated and kept with foster cow system were (Figure 4). There were no significant differences between the 3 cow-calf management systems involving early separation in how much more likely participants were WTP same or more for milk compared with what they currently pay for milk.
Interestingly, out of country and other socio-demographic factors, only gender (Wald $\chi^{2}=17.79 ; P<$ 0.001 ) and industry familiarity (Wald $\chi^{2}=5.85 ; P=$ 0.016) affected participants' WTP for milk. Participants in our study who identified as female had a log-odds regression coefficient of $-0.57 \pm 0.13(P<0.0001)$, suggesting that they were less likely to be WTP same or more for milk (compared with what they currently pay) than participants who did not identify as female. Clark et al. (2017) found that women were generally more likely to be WTP more for "welfare-friendly" products than men in their meta-analysis of WTP for farm animal welfare. Thus, given that participants in this study who identified as female had more negative attitudes 


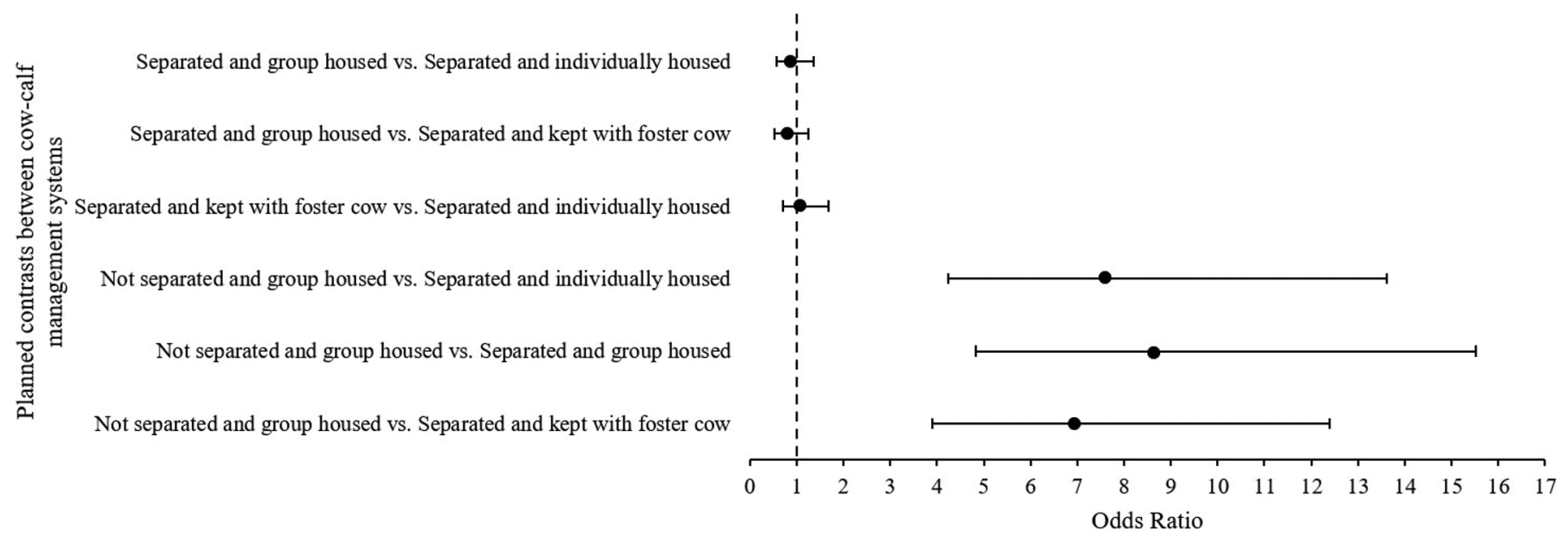

Figure 4. The estimated odds ratios and their 99\% Wald confidence limits of willingness to pay (WTP) same or more for milk from planned contrasts performed between each of the 4 different cow-calf management systems, following a binary logit model testing the effects of sociodemographics and cow-calf management system on participants' $(\mathrm{n}=1,311) \mathrm{WTP}$ same or more for milk from their given system compared with what they currently pay for milk. Each participant was randomly assigned to 1 of 4 scenarios that each described a different cow-calf management system. The circular points in the graph represent the odds ratio values. The horizontal lines extending to the left and right of each point represent the confidence interval for each planned contrast, with the lower and upper bounds of the $99 \%$ Wald confidence limits represented by the left and right ends of these lines, respectively. Planned contrasts with confidence intervals that do not include 1 (i.e., that do not cross the vertical dashed line crossing the $\mathrm{x}$-axis at $\mathrm{x}=1$ ) mean that we reject the null hypotheses for these planned contrasts that the odds ratio equals 1$)$.

toward and lower perceptions of animal welfare within their given cow-calf management systems than participants who did not identify as female, it is not surprising that they were also less likely to be WTP same or more for milk from these given management systems that they perceived more negatively than participants who did not identify as female. Taken together, our results suggest that gender effects were consistent across the outcome measures in this study, with participants who identified as female having lower attitudes toward their given cow-calf management system, lower perceptions of animal welfare within that system, and being less likely to be WTP the same or more for milk from that system (compared with what they currently pay) than participants who did not identify as female.

In contrast, industry familiarity had a positive logodds regression coefficient of $0.13 \pm 0.06(P=0.016)$, suggesting that the more familiar participants reported being with the dairy industry, the more likely they were to be WTP same or more for milk from their given system compared with what they currently pay for milk. This is consistent with reports of people with more industry familiarity being less concerned with modern production practices (Clark et al., 2016), and thus, probably more likely to be supportive of the production industry, which may be displayed in their reported WTP for industry products. In this case too, the effect of industry familiarity was consistent across the outcome measures in this study, with participants who reported higher industry familiarity having more positive attitudes toward their given cow-calf management system, higher perceptions of animal welfare within that system, and being more likely to be WTP the same or more for milk from that system (compared with what they currently pay) than participants who reported being less familiar with the dairy industry.

It is important to note that WTP questions are an imperfect indicator of actual purchasing behavior ( $\mathrm{Li}$ ebe et al., 2011; Norwood and Lusk, 2011). Responses to these questions can be affected by other factors, such as access to and knowledge of products and perception of product quality or nutritional value (Vermeir and Verbeke, 2006; Liebe et al., 2011; de Graaf et al., 2016; Clark et al., 2017; Miranda-de la Lama et al., 2017). However, with an established link between perceptions and consumption behaviors, WTP can and has been used as another indicator of public perceptions of farm animal welfare (Clark et al., 2017). Thus, these results of participants being more likely to be WTP the same or more for milk from a system involving no early cow-calf separation is consistent with and supportive of the study findings that participants had both a less negative attitude toward the not separated and group housed system and a less negative perception of the welfare of cows and calves in this system. This finding is also in line with a growing number of studies reporting higher WTP for products from "welfare-friendly" production systems compared with standard systems or 
those perceived as less "welfare-friendly" (e.g., Napolitano et al., 2008; de Graaf et al., 2016; Miranda-de la Lama et al., 2017; and reviewed by Clark et al., 2017).

\section{Qualitative Findings}

The results reviewed above, in particular the high internal consistency participants displayed in their attitudes toward the system and in their perceptions of different animal welfare aspects within the system, indicate that participants often took a holistic and highly value-oriented view of the rearing system. However, in their qualitative responses, participants also demonstrated nuanced views regarding cow-calf management. The diversity of views encompassed a wide range of concerns and arguments distributed across 6 themes: impact on animals, cow-calf relationship, use of animals and animal products, standard of care, production, and knowledge reflection (see Table 4). These themes were brought up by participants across all 4 treatments but in some cases included different attitude valences (i.e., positive, neutral, or negative) toward treatments. These themes and their subthemes are discussed below.

Impact on Animals. Participants brought up subthemes consistent with Fraser et al.'s (1997) animal welfare construct, raising concerns regarding the animals' affective states (or feelings), animals' ability to perform natural behaviors (or naturalness), and biological functioning (including health). These responses have been reported by others; for example, when investigating perspectives on early cow-calf separation (Ventura et al., 2013) and heat stress in dairy cattle (Cardoso et al., 2018).

Interestingly, many participants, regardless of which system they were asked to evaluate, were concerned about how the cows and the calves would feel following separation: "The calf should be with the cow, when you separate them it affects them emotionally" (US1289; separated and kept with foster cow system) and "[...] the calf is probably scared because it's being separated from its mother [...] On the flip side the mother is probably super depressed after being separated from her calf [...]" (CA97; separated and individually housed system).

Some participants voiced concerns about naturalness (nature or a natural state), arguing that any system that separated cows from their calves was in contradiction to this view of naturalness: "It is inhumane to separate them and not allow natural bonding" (US1615; separated and group housed system) and "I feel the calf should be with his mother cow to nurse as that is the most natural thing in nature to do" (US1064; separated

Table 4. Themes and subthemes referenced by participants to describe their views regarding cow-calf management systems

\begin{tabular}{|c|c|c|}
\hline Theme & Subtheme & Description \\
\hline Standard of care & & $\begin{array}{l}\text { Discussion of the quality, humaneness, or appropriateness of care provided to } \\
\text { the animals in the management system }\end{array}$ \\
\hline Production & $\begin{array}{l}\text { Dissatisfaction with } \\
\text { motivations; dairy farming } \\
\text { structure, change; milk } \\
\text { production }\end{array}$ & $\begin{array}{l}\text { Discussion of management decisions and implications at a farm and industry } \\
\text { level: disapproval of actions or motivations behind production practice or } \\
\text { system; discussion of how farms operate or are structured, and whether or not } \\
\text { they can or should change; production of milk, including for farmer }\end{array}$ \\
\hline
\end{tabular}


and kept with foster cow system). Participant concerns regarding loss of naturalness have been reported in previous studies investigating attitudes toward cowcalf separation (North America, Ventura et al., 2013; United States and Germany, Busch et al., 2017; Brazil, Hötzel et al., 2017).

Participants in our study also raised concerns regarding the health of the calf, frequently referring to calf nutrition, as opposed to concerns over disease risk. When disease risk was discussed, it was usually in terms of how the mother's milk could help mitigate disease risk in the calf: "[...] The calf needs a lot of immunity it gets only from their cow's (mother's) milk. The calf wants to be healthy and free from diseases, it needs cow milk [...]" (CA22; separated and kept with foster cow system) and "[...] This method [not separating cow and calf...] results in a healthier calf because the calf is able to receive the antibodies for the mother that is critical for good health" (US637; not separated and group housed system). In contrast, participants that were supportive of separation in the Ventura et al. (2013) study frequently commented on their belief that increased cow-calf contact increased disease risk. The latter finding is not surprising given that many of the participants in the study by Ventura at al. (2013) were farmers or veterinarians who worked in the dairy industry. In contrast, most participants in the current study likely had little knowledge of the dairy industry and focused on the calves and their ability to have access to not only milk but also their mothers. This view included those participants that were presented the foster cow scenario: "It seems a bit cruel to the calves that won't get the benefits of their own mother's antibodies before they are separated. I don't know if they will get the same benefits from other cows" (US934; separated and kept with foster cow system). This finding suggests that any cow-calf management system that does not allow for contact between cows and their own calves may be viewed as inadequate.

Cow-Calf Relationship. The emphasis that the public places on the perceived importance of the cowcalf relationship has been discussed by others (e.g., Ventura et al., 2013 and Busch et al., 2017). Not surprisingly, participants in the current study also highlighted the presence and importance of separation distress and the effect of the cow-calf relationship, or a lack of such a relationship, on levels of distress: "There is general awareness that cows and calves have an emotional life and the bond between cow and calf is a concern if separated because it ultimately ends in distress for the calf" (CA176; separated and group housed system) and "It is cruel to separate a mother and her calf and causes stress and anxiety [...]" (US1050; separated and group housed system).
Although the majority of participants referencing concerns surrounding the cow-calf relationship and animal feelings were against the practice of early separation, some participants were in favor of early cowcalf separation, as also noted by Ventura et al. (2013). However, in the study by Ventura et al. (2013), in which many participants supported early separation, cited health risks and the increased distress responses observed the longer the cow-calf pair has been together, the participants in our study who favored early separation focused almost exclusively on the latter point: "Better [that cow and calf are] removed at once before a bond can form" (US1692; separated and kept with foster cow system). Increased vocalizations from cows and calves have been observed in cases of separation performed more than $24 \mathrm{~h}$ but before 2 wk postcalving (Weary and Chua, 2000; Flower and Weary, 2001). However, other studies where separation was performed after $45 \mathrm{~d}$ report decreased distress response in both cows (Pérez-Torres et al., 2016; Stěhulová et al., 2017) and calves (Stěhulová et al., 2017). In contrast to the greater focus placed on separation response as opposed to health risks by our participants, the focus on health risks exhibited by participants in the study by Ventura et al. (2013) could be due in part to the fact that their study included more participants with self-reported involvement with the dairy industry (69\% of participants compared with only $2.3 \%$ of participants in our study). Calf management and how it relates to mortality and disease risk are areas of ongoing research and concern in the dairy industry (e.g., Vasseur et al., 2010; Winder et al., 2018).

Some participants also drew connections between the cow-calf relationship and the human parent-child relationship. These participants often questioned the acceptability of breaking any parent-offspring bond: "The idea of separating a mother from their offspring is upsetting. Just because they're animals and they can't stand up for themselves, doesn't mean they don't feel the mother-child connection. It is devastating to hear that they are separated right after birth, an offspring needs their mother" (CA7; separated and individually housed system) and "It's cruel to take a baby away from mother regardless of human or animal" (US455; separated and individually housed system).

Use of Animals and Animal Products. Some participants defended their specific attitudes toward the described cow-calf management systems by bringing up their views of the use of animals and animal products in general. A few participants expressed views on ethics consistent with views supporting abolition of all animal use (Beauchamp et al., 2008; Munro, 2012; Lund et al., 2019): "Shouldn't be allowed to farm cows for meat or milk" (US36; not separated and group housed sys- 
tem). However, others took a more utilitarian approach (Beauchamp et al., 2008; Lund et al., 2019), bringing up costs and benefits and arguing that it was also important to consider the importance of dairy as a human food source, including nutritional consequences of dairy consumption, and necessity of such consumption [e.g., "While it is not right to take away the baby from its mother, we need the milk as humans" (US819; separated and individually housed system)], or, lack of necessity [e.g., "There is no need for humans to consume cow milk as it's not healthy for humans. There are many other sources of calcium and protein [...]" (US441; separated and group housed system)]. These types of responses often brought up considerations that included having to balance dairy consumption with how animals are used by people. There is much discussion on the association between dairy consumption and a healthy diet (i.e., Pereira, 2014). However, the growing concerns regarding animals used for human consumption has also increased discussions associated with limiting consumption of animal products (Haverstock and Forgays, 2012; Ruby, 2012).

In contrast to justifying their attitudes in relation to their beliefs surrounding the use of animals and animal products, other participants justified their beliefs and practices on this issue in terms of their own future actions and thoughts given the new knowledge about how cows and calves are cared for: "I am really saddened to learn this, both as a human being and a lover of animals. It makes me a lot more self-conscious about what I consume as food products and have more thoughts about the process in which these products are created. It is absolutely shocking to hear how cruel and inhuman the process is. The poor animals are disposable and not looked at as living life forms with emotions. Imagine doing this to a person, how appropriate and sane would that be to do? Any baby needs their mother. Consumerism needs to change and animals need to be treated with decency." (CA223; separated and kept with foster cow system) and "This is disappointing to learn. I think if more customers of dairy milk were educated [on] this process they would be reluctant to purchase dairy milk" (US661; separated and kept with foster cow system). As awareness of cow-calf separation increases throughout society there is risk that this may elicit behavioral change in purchasing behavior (Ventura et al., 2013, 2016). One study showed changes in purchasing habits of UK participants who reported an interest in more information on production practices and a willingness to pay more for practices that would improve welfare (Ellis et al., 2009).

Standard of Care. Concerns for how animals are used by people were also expressed by the participants, particularly when associated with the practice of early separation (i.e., those that received descriptions of the separated and group housed, separated and kept with foster cow, or separated and individually housed systems); words such as "unacceptable," "inhumane," or "cruel" were used and often in conjunction with a total rejection of the system. For example, "I believe that this management system is entirely unethical and cruel" (US952; separated and group housed system; attitude score of 1) and "Separating a calf after birth from the mom is totally unacceptable and inappropriate whatever living being it is" (CA141; separated and individually housed system; attitude score of 2). In contrast, participants who were presented with the not separated and group housed system often used words that implied that they viewed the animals were cared for appropriately, such as "I totally agree with this system, because the cow and calves do not get separated at birth, the other way around would be animal cruelty [...]" (CA262; not separated and group housed system; attitude score of 6.67) and "I believe it is perfectly fine and acceptable pairing and housing the cow and calf together. This is decent and humane treatment, as it should be" (US1125; not separated and group housed system; attitude score of 7$)$.

The perceived relationship between standard of care given by the farmer and perceptions of animal welfare also arose in the responses. This concept that farmers must uphold a certain standard of care and that this is owed to the animals is not new; the idea is that humans have a duty to care for animals as a result of our relationships with them, particularly when this relationship is one in which we profit from (Engster, 2006). Weary and Robbins (2019) discuss this as the public's desire for "humane care," often in combination with an assumption that a "duty of care" to animals is inherent to being a farmer. Concerns for providing animals with an owed standard of care have also been reported in studies investigating public conceptions of an ideal dairy farm (Cardoso et al., 2016) and an ideal pig farm (Sato et al., 2017). Such concerns point to a focus on a human-animal interaction dimension of animal welfare. This suggests an acknowledgment of the responsibility humans may have in providing for the animals that we use for production purposes or even just interact with on any level. This could have important implications for the social licensing of production practices (see Rollin 2011 for further discussion on this topic), especially for any practices perceived to compromise a minimum standard of care.

Production. Some participants were dissatisfied and had clear expectations that the animals be treated to a higher standard than what is presently given to the animals. For example, in the voice of one participant: "I think it's cruel to produce milk this way by using cows 
to give birth then take calves away so farmers can take the milk from the cows" (US1630; separated and group housed system). This concern around the "exploitation" of cows for milk production has been noted by others regarding the public's view on cow-calf separation (Ventura et al., 2013) but also in reports summarizing the public's views on how cows and other farm animals are used solely for production goals without consideration for animals' welfare and management (Boogaard et al., 2006, 2011).

Some participants also questioned the ability and willingness of farmers and the industry to change current management practices. Some participants discussed the idea of change as a barrier, a point also raised by previous participants asked about cow-calf separation (Ventura et al., 2013; Busch et al., 2017). Interestingly, some participants that were in the Not separated and group housed system stated the ability to change as a positive, or as a call to move away from the negatively perceived practice of early separation inherent to the separated and kept with foster cow, separated and group housed, and separated and individually housed systems.

Although many participants expressed their dissatisfaction with motivations and the failure by the industry to change, some participants expressed support of farmers and milk production. In the latter case, concerns often were in relation to the effect on the farmers' livelihoods, with some participants citing milk production concerns as a means to support the practice of early cow-calf separation: "A dairy is a business, and in order to run the business, the farmer must separate cows and calves to get milk to sell to stores, and make his business successful" (US1533; separated and group housed) and "How else would we get milk if they do not separate them" (US1419; separated and group housed system). However, concerns about milk production were also used by participants in support of the not separated and group housed system which did not employ early separation practices, "I think it's good the mother gets to stay with the baby calf and nurse as well, as this will likely stimulate the mother to produce more milk and improve the mental health of wellbeing of the mother and the calf' (CA284; not separated and group housed system).

Both the concern that milk production may be reduced by nursing and the contrasting belief that it may be increased when the calf is able to nurse were also highlighted by Ventura et al. (2013). These conflicting concerns are also the topics of research; a recent systematic review summarizing this body of research suggests that although cows will temporarily produce less saleable milk when nursing calves, this reduction in saleable milk yield may be balance out over the entire lactation cycle, depending on when suckling calves are weaned (Meagher et al., 2019).

Knowledge Reflection. Some participants reflected on how they organized or weighed their own perceptions and the amount of knowledge they felt that they had or was relevant to the formation of their attitude toward their given system. Although some participants conveyed very one-sided opinions (either heavily in favor or against separation), others were more nuanced and addressed multiple, even conflicting, concerns, and themes. These latter participants discussed trade-offs, and concerns about balancing the interests of animals and that of different stakeholders. For example, some participants discussed the importance of integrating production with proper care and concern for all animals involved: "It [not separating cows and calves] encourages the natural bonding and milk production in the cow-calf management. It seems ethical and less stressful for the animals" (US1568; not separated and group housed system), and "I believe that separating the calf from its mother immediately after birth is not ideal for the mother and calf from an emotional standpoint of the cow. At the same time milk and its by-products are an integral part of the human diet. It would be better if the calf can obtain milk from its mother directly and be balanced/alternated with milking by the farmer" (CA169; separated and individually housed system).

Equally interesting was that although many participants expressed concerns for the animals and their welfare, many also expressed concerns for the farmers and for all members of society who rely on animals for food. Examples of this nuanced concern for both the animals and the farmers include: "Hard on the emotional side to know a mother and her child [are] separated, but know [this] is needed for the efficiency of the farmers" (CA188; separated and individually housed system; no industry involvement) and "I feel the calf should be able to stay with the birthing cow a little longer. But I also understand that a cow is only able to produce milk within certain limits" (US843; separated and kept with foster cow system; no industry involvement). This expression of concern for both the farmers and for the animals was also noted by Cardoso et al. (2016) and by Sato et al. (2017) after asking participants to describe characteristics they considered most important to an ideal dairy farm or pig farm, respectively. Such findings suggest the importance of emphasis on the one welfare approach (e.g., Tarazona et al., 2019); how improving conditions for farmers could benefit animals and vice versa.

That some participants acknowledged that there are alternate viewpoints did not mean that they were necessarily persuaded or even agreed with these. Rather, they acknowledged and appeared to respect that others 
may think differently, but overall retained their own opposing or contrary viewpoint. This further suggests the highly value-oriented approach many participants took toward the issue of cow-calf separation. For example, participant CA106 still maintained a negative attitude toward the separated and individually housed system (score of 3.33) despite acknowledging alternate "economic and morality sides" of the argument in support of the separated and individually housed system. That some participants empathized with farmers and industry-specific concerns (e.g., economic constraints) was also discussed by Benard and de Cock Buning (2013) who interviewed pig farmers and urban citizens. The citizens reflected that pig farming was, in their view, a difficult profession and although they did not agree with many aspects of pig housing, they also acknowledged that change could not take place overnight, instead requesting that the farmers try to do better.

\section{Implications and Future Directions}

Ultimately, our results provide insight into a range of public views expressed on cow-calf management systems varying in the type of social and maternal contact provided. Future studies with different participant samples are needed to further investigate views in different countries outside North America and across a wider range of socio-demographics. In particular, incorporation of more participants with involvement in the dairy industry (e.g., veterinarians, farmers) is necessary to better address the views of more stakeholders. This is especially important given the different levels of emphasis placed on different aspects of animal welfare (i.e., including but not limited to health, emotions, naturalness, standard of care) by different stakeholders (Lassen et al., 2006; Vanhonacker et al., 2008). Furthermore, the use of participatory methodologies (van Dijk et al., 2017; Bolton and von Keyserlingk, 2021) may provide opportunities to help ease tensions between different stakeholder groups and facilitate discussions on mutually developed improvements to complex conventional practices such as early cow-calf separation.

However, that our participants tended to focus most on concerns about the cow-calf relationship (in particular, the issue of separation itself) and how early separation is a breach of standard of care ultimately brings into question the social sustainability of alternative management practices that still require separation from the mother. Clearly any system that involves removing the calf from its mother was a key concern for most participants, profoundly affecting their perceptions of animal welfare within any of the cow-calf management systems that involved separation and their overall attitudes toward these systems. This concern also appeared to affect participants' reported WTP for milk from these systems in comparison to what they currently pay (for participants who believed these systems were different from the system they currently buy milk from). Despite some industry stakeholders suggesting that a foster cow system may be a potentially viable solution moving forward (as discussed by Kälber and Barth, 2014), our work indicates that this system will likely not be accepted by members of the public in Canada and the United States. Overall, the participants in our study struggled with the breaking of the parentoffspring bond and this resulted in their rejection of any system that included this aspect. Similar to the failure of the modified cage as a socially acceptable and widely adopted alternate housing system for laying hens in part due to its inability to address public concerns (Weary et al., 2016), the results of our study suggest that alternative cow-calf management systems that do not address public concerns surrounding the breaking of the parent-offspring bond will not be acceptable. Although our WTP findings indicate that participants that received the cow-calf contact scenario indicated that they were more likely to be WTP the same or more for milk from this system than would participants who received early separation scenarios, more research is needed to determine if this translates into changes in purchasing behavior. Ultimately, more research into the feasibility of alternate systems that address public concerns by not involving the early breaking of this bond is also necessary, alongside more research to address other key stakeholders' (e.g., farmers' and veterinarians') perceptions of barriers to such systems.

\section{CONCLUSIONS}

After reading a brief description of cow-calf management systems differing in types of social and maternal contact allowed, participants had negative attitudes toward and negative perceptions of animal welfare within all systems involving early cow-calf separation. This negative assessment of systems involving early cow-calf separation extended even to options thought to provide benefits to calves over the standard practice of early separation followed by individual housing by providing calves with social companions through group housing or by providing substitute maternal contact with foster cows after early cow-calf separation. Of key concern to many participants was the perception of the inherent importance of the mother cow-calf relationship, and that early separation was a breach of standard of care owed to both cows and calves. Collectively these results suggest that participants are largely unwilling to compromise when it comes to finding alternatives to the practice of early cow-calf separation. 


\section{ACKNOWLEDGMENTS}

We thank all the participants in this study for sharing their views. We thank Katelyn Mills, Kenny Go, Thomas Ede, and members of the UBC Animal Welfare Program (Vancouver, BC, Canada) for input and feedback during various stages of the study. Funding for this research was provided by the Hans Sigrist Research Prize (Bern, Switzerland) awarded to Marina von Keyserlingk (Animal Welfare Program, Vancouver, BC, Canada). The authors have not stated any conflicts of interest.

\section{REFERENCES}

Ajzen, I., and M. Fishbein. 2000. Attitudes and the attitude-behavior relation: Reasoned and automatic processes. Eur. Rev. Soc. Psychol. 11:1-33. https://doi.org/10.1080/14792779943000116.

Alonso, M. E., J. R. González-Montaña, and J. M. Lomillos. 2020 Consumers' concerns and perceptions of farm animal welfare. Animals (Basel) 10:385. https://doi.org/10.3390/ani10030385.

Bartholomew, D. J., M. Knott, and I. Moustaki. 2011. Latent Variable Models and Factor Analysis: A Unified Approach. 3rd ed. Jon Wiley \& Sons.

Beardsworth, A., A. Bryman, T. Keil, J. Goode, C. Haslam, and E. Lancashire. 2002. Women, men and food: The significance of gender for nutritional attitudes and choices. Br. Food J. 104:470-491. https://doi.org/10.1108/00070700210418767.

Beauchamp, T. L., F. B. Orlans, R. Dresser, D. B. Morton, and J. P. Gluck. 2008. Moral issues about animals. Pages 3-44 in The Human Use of Animals: Case Studies in Ethical Choice. 2nd ed. Oxford University Press, Inc.

Beaver, A., R. K. Meagher, M. A. G. von Keyserlingk, and D. M. Weary. 2019. Invited review: A systematic review of the effects of early separation on dairy cow and calf health. J. Dairy Sci. 102:5784-5810. https://doi.org/10.3168/jds.2018-15603.

Benard, M., and T. de Cock Buning. 2013. Exploring the potential of Dutch pig farmers and urban-citizens to learn through frame reflection. J. Agric. Environ. Ethics 26:1015-1036. https://doi.org/ 10.1007/s10806-013-9438-y.

Berger, R. 2015. Now I see it, now I don't: researcher's position and reflexivity in qualitative research. Qual. Res. 15:219-234. https:// doi.org/10.1177/1468794112468475.

Bolton, S. E., and M. A. G. von Keyserlingk. 2021. The dispensable surplus dairy calf: Is this issue a "wicked problem" and where do we go from here? Front. Vet. Sci. 8:660934. https://doi.org/10 .3389 /fvets.2021.660934.

Boogaard, B. K., B. B. Bock, S. J. Oosting, and E. Krogh. 2010. Visiting a farm: An exploratory study of the social construction of animal farming in Norway and the Netherlands based on sensory perception. Int. J. Sociol. Agric. Food 17:24-50. https://doi.org/ 10.48416/ijsaf.v17i1.266.

Boogaard, B. K., B. B. Bock, S. J. Oosting, J. S. C. Wiskerke, and A. J. van der Zijpp. 2011. Social acceptance of dairy farming: The ambivalence between the two faces of modernity. J. Agric. Environ. Ethics 24:259-282. https://doi.org/10.1007/s10806-010 -9256-4.

Boogaard, B. K., S. J. Oosting, and B. B. Bock. 2006. Elements of societal perception of farm animal welfare: A quantitative study in the Netherlands. Livest. Sci. 104:13-22. https://doi.org/10.1016/ j.livsci.2006.02.010.

Boogaard, B. K., S. J. Oosting, and B. B. Bock. 2008. Defining sustainability as a socio-cultural concept: Citizen panels visiting dairy farms in the Netherlands. Livest. Sci. 117:24-33. https://doi.org/ 10.1016/j.livsci.2007.11.004.

Buchli, C., A. Raselli, R. Bruckmaier, and E. Hillmann. 2017. Contact with cows during the young age increases social competence and lowers the cardiac stress reaction in dairy calves. Appl. Anim. Behav. Sci. 187:1-7. https://doi.org/10.1016/j.applanim.2016.12.002.

Busch, G., D. M. Weary, A. Spiller, and M. A. G. von Keyserlingk. 2017. American and German attitudes towards cow-calf separation on dairy farms. PLoS One 12:e0174013. https://doi.org/10.1371/ journal.pone. 0174013 .

Cantor, M. C., H. W. Neave, and J. H. C. Costa. 2019. Current perspectives on the short- and long-term effects of conventional dairy calf raising systems: A comparison with the natural environment. Transl. Anim. Sci. 3:549-563. https://doi.org/10.1093/tas/txy144.

Cardoso, C. S., M. J. Hötzel, D. M. Weary, J. A. Robbins, and M. A. G. von Keyserlingk. 2016. Imagining the ideal dairy farm. J. Dairy Sci. 99:1663-1671. https://doi.org/10.3168/jds.2015-9925.

Cardoso, C. S., M. A. G. von Keyserlingk, M. J. Hötzel, J. Robbins, and D. M. Weary. 2018. Hot and bothered: Public attitudes towards heat stress and outdoor access for dairy cows. PLoS One 13:e205352. https://doi.org/10.1371/journal.pone.0205352.

Chandler, J., C. Rosenzweig, A. J. Moss, J. Robinson, and L. Litman. 2019. Online panels in social science research: Expanding sampling methods beyond Mechanical Turk. Behav. Res. Methods 51:20222038. https://doi.org/10.3758/s13428-019-01273-7.

Clark, B., G. B. Stewart, L. A. Panzone, I. Kyriazakis, and L. J. Frewer. 2016. A systematic review of public attitudes, perceptions and behaviours towards production diseases associated with farm animal welfare. J. Agric. Environ. Ethics 29:455-478. https://doi .org/10.1007/s10806-016-9615-x.

Clark, B., G. B. Stewart, L. A. Panzone, I. Kyriazakis, and L. J. Frewer. 2017. Citizens, consumers and farm animal welfare: A meta-analysis of willingness-to-pay studies. Food Policy 68:112-127. https://doi.org/10.1016/j.foodpol.2017.01.006.

Codron, J., K. Grunert, E. Giraud-Heraud, L. Soler, and A. Regmi. 2005. Retail sector responses to changing consumer preferences: The European experience. Pages 32-46 in New Directions in Global Food Markets. Agriculture Information Bulletin No. 794. Economic Research Service, USDA. Accessed May 18, 2021. https:// www.ers.usda.gov/publications/pub-details/?pubid $=42591$.

Costa, J. H. C., M. A. G. von Keyserlingk, and D. M. Weary. 2016. Invited review: Effects of group housing of dairy calves on behavior cognition, performance, and health. J. Dairy Sci. 99:2453-2467. https://doi.org/10.3168/jds.2015-10144.

de Graaf, S., E. J. Van Loo, J. Bijttebier, F. Vanhonacker, L. Lauwers, F. A. M. Tuyttens, and W. Verbeke. 2016. Determinants of consumer intention to purchase animal-friendly milk. J. Dairy Sci. 99:8304-8313. https://doi.org/10.3168/jds.2016-10886.

Ellis, J. L. 2016. Factor analysis and item analysis. Part VII. Pages 3-151 in Applying Statistics in Behavioural Research. 1st ed. Boom.

Ellis, K. A., K. Billington, B. McNeil, and D. E. F. McKeegan. 2009. Public opinion on UK milk marketing and dairy cow welfare. Anim. Welf. 18:267-282.

Engster, D. 2006. Care ethics and animal welfare. J. Soc. Philos. 37:521-536. https://doi.org/10.1111/j.1467-9833.2006.00355.x.

Flower, F. C., and D. M. Weary. 2001. Effects of early separation on the dairy cow and calf: 2 . Separation at 1 day and 2 weeks after birth. Appl. Anim. Behav. Sci. 70:275-284. https://doi.org/10 .1016/S0168-1591(00)00164-7.

Flower, F. C., and D. M. Weary. 2003. The effects of early separation on the dairy cow and calf. Anim. Welf. 12:339-348.

Fraser, D., D. M. Weary, E. A. Pajor, and B. N. Milligan. 1997. A scientific conception of animal welfare that reflects ethical concerns. Anim. Welf. 6:187-205.

Friborg, O., M. Martinussen, and J. H. Rosenvinge. 2006. Likert-based vs. semantic differential-based scorings of positive psychological constructs: A psychometric comparison of two versions of a scale measuring resilience. Pers. Individ. Dif. 40:873-884. https://doi .org/10.1016/j.paid.2005.08.015.

Gómez-Corona, C., H. B. Escalona-Buendía, M. García, S. Chollet, and D. Valentin. 2016. Craft vs. industrial: Habits, attitudes and motivations towards beer consumption in Mexico. Appetite 96:358-367. https://doi.org/10.1016/j.appet.2015.10.002. 
Grunert, K. G., W. I. Sonntag, V. Glanz-Chanos, and S. Forum. 2018. Consumer interest in environmental impact, safety, health and animal welfare aspects of modern pig production: Results of a cross-national choice experiment. Meat Sci. 137:123-129. https:// doi.org/10.1016/j.meatsci.2017.11.022.

Guest, G., K. M. MacQueen, and E. E. Namey. 2014. Applied Thematic Analysis. SAGE Publications, Inc. https://doi.org/10.4135/ 9781483384436

Haverstock, K., and D. K. Forgays. 2012. To eat or not to eat. A comparison of current and former animal product limiters. Appetite 58:1030-1036. https://doi.org/10.1016/j.appet.2012.02.048.

Hötzel, M. J., C. S. Cardoso, A. Roslindo, and M. A. G. von Keyserlingk. 2017. Citizens' views on the practices of zero-grazing and cow-calf separation in the dairy industry: Does providing information increase acceptability? J. Dairy Sci. 100:4150-4160. https:// doi.org/10.3168/jds.2016-11933.

Hötzel, M. J., C. Longo, L. F. Balcão, C. S. Cardoso, and J. H. C. Costa. 2014. A survey of management practices that influence performance and welfare of dairy calves reared in Southern Brazil. PLoS One 9:e114995. https://doi.org/10.1371/journal.pone.0114995.

Hudson, S. J. 1977. Multiple fostering of calves onto nurse cows at birth. Appl. Anim. Ethol. 3:57-63. https://doi.org/10.1016/0304 -3762(77)90071-2.

Johnson, R. B., and A. J. Onwuegbuzie. 2004. Mixed methods research: A research paradigm whose time has come. Educ. Res. 33:14-26. https://doi.org/10.3102/0013189X033007014.

Kälber, T., and K. Barth. 2014. Practical implications of suckling systems for dairy calves in organic production systems - A review. Landbauforschung 64:45-58. https://doi.org/10.3220/LBF_2014 $-45-58$.

Kent, J. P. 2020. The cow-calf relationship: From maternal responsiveness to the maternal bond and the possibilities for fostering. J. Dairy Res. 87(S1):101-107. https://doi.org/10.1017/ S0022029920000436.

Krohn, C. C., J. Foldager, and L. Mogensen. 1999. Long-term effect of colostrum feeding methods on behaviour in female dairy calves. Acta Agric. Scand. A Anim. Sci. 49:57-64. https://doi.org/10 $.1080 / 090647099421540$.

Landis, J. R., and G. G. Koch. 1977. The measurement of observer agreement for categorical data. Biometrics 33:159-174. https://doi .org/10.2307/2529310.

Lassen, J., P. Sandøe, and B. Forkman. 2006. Happy pigs are dirty! - Conflicting perspectives on animal welfare. Livest. Sci. 103:221230. https://doi.org/10.1016/j.livsci.2006.05.008.

Liebe, U., P. Preisendörfer, and J. Meyerhoff. 2011. To pay or not to pay: Competing theories to explain individuals' willingness to pay for public environmental goods. Environ. Behav. 43:106-130. https://doi.org/10.1177/0013916509346229.

Lund, T. B., S. V. Kondrup, and P. Sandøe. 2019. A multidimensional measure of animal ethics orientation - Developed and applied to a representative sample of the Danish public. PLoS One 14:e0211656. https://doi.org/10.1371/journal.pone.0211656.

Lutz, J. 2016. The validity of crowdsourcing data in studying anger and aggressive behavior: A comparison of online and laboratory data. Soc. Psychol. (Gott.) 47:38-51. https://doi.org/10.1027/ 1864-9335/a000256.

Lyford, C., J. Thompson, R. Polkinghorne, M. Miller, T. Nishimura, K. Neath, P. Allen, and E. Belasco. 2010. Is willingness to pay (WTP) for beef quality grades affected by consumer demographics and meat consumption preferences? Australas. Agribus. Rev. $18: 1-17$.

McKendree, M. G. S., C. C. Croney, and N. J. O. Widmar. 2014. Effects of demographic factors and information sources on United States consumer perceptions of animal welfare. J. Anim. Sci. 92:3161-3173. https://doi.org/10.2527/jas.2014-6874.

McKendree, M. G. S., N. J. Olynk, and D. L. Ortega. 2012. Consumer preferences and perceptions on food safety, production practices and food product labeling: A spotlight on dairy product purchasing behavior in 2011. CAB RP 12.1. Center for Food and Agricultural Business, Purdue University. Accessed Feb. 10, 2021. https: //agribusiness.purdue.edu/wp-content/uploads/2019/08/r-1-2012 -mckendree-olynk-ortega.pdf.

Mdegela, R. H., L. J. M. Kusiluka, A. M. Kapaga, E. D. Karimuribo, F. M. Turuka, A. Bundala, F. Kivaria, B. Kabula, A. Manjurano, T. Loken, and D. M. Kambarage. 2004. Prevalence and determinants of mastitis and milk-borne zoonoses in smallholder dairy farming sector in Kibaha and Morogoro districts in Eastern Tanzania. J. Vet. Med. B Infect. Dis. Vet. Public Health 51:123-128. https://doi.org/10.1111/j.1439-0450.2004.00735.x.

Meagher, R. K., A. Beaver, D. M. Weary, and M. A. G. von Keyserlingk. 2019. Invited review: A systematic review of the effects of prolonged cow-calf contact on behavior, welfare, and productivity. J. Dairy Sci. 102:5765-5783. https://doi.org/10.3168/jds.2018 $-16021$

Miles, M. B., A. M. Huberman, and J. Saldaña. 2014. Qualitative Data Analysis: A Methods Sourcebook. 3rd ed. Sage Publications Inc.

Miranda-de la Lama, G. C., L. X. Estévez-Moreno, W. S. Sepúlveda, M. C. Estrada-Chavero, A. A. Rayas-Amor, M. Villarroel, and G. A. María. 2017. Mexican consumers' perceptions and attitudes towards farm animal welfare and willingness to pay for welfare friendly meat products. Meat Sci. 125:106-113. https://doi.org/10 .1016/j.meatsci.2016.12.001.

Munro, L. 2012. The animal rights movement in theory and practice: A review of the sociological literature. Sociol. Compass 6:166-181. https://doi.org/10.1111/j.1751-9020.2011.00440.x.

Napolitano, F., C. Pacelli, A. Girolami, and A. Braghieri. 2008. Effect of information about animal welfare on consumer willingness to pay for yogurt. J. Dairy Sci. 91:910-917. https://doi.org/10.3168/ jds.2007-0709.

Newberry, R. C., and J. C. Swanson. 2008. Implications of breaking mother-young social bonds. Appl. Anim. Behav. Sci. 110:3-23. https://doi.org/10.1016/j.applanim.2007.03.021.

Nijland, H. J., N. Aarts, and C. M. J. van Woerkum. 2018. Exploring the framing of animal farming and meat consumption: On the diversity of topics used and qualitative patterns in selected demographic contexts. Animals (Basel) 8:17. https://doi.org/10 $.3390 /$ ani8020017.

Norwood, F. B., and J. L. Lusk. 2011. A calibrated auction-conjoint valuation method: Valuing pork and eggs produced under differing animal welfare conditions. J. Environ. Econ. Manage. 62:80-94. https://doi.org/10.1016/j.jeem.2011.04.001.

Onwuegbuzie, A. J., and J. P. Combs. 2015. Emergent data analysis techniques in mixed methods research: A synthesis. Pages 1-46 in SAGE Handbook of Mixed Methods in Social \& Behavioral Research. Tashakkori, A., and C. Teddlie, ed. SAGE Publications, Inc. https://doi.org/10.4135/9781506335193.n17.

Oppenheimer, D. M., T. Meyvis, and N. Davidenko. 2009. Instructional manipulation checks: Detecting satisficing to increase statistical power. J. Exp. Soc. Psychol. 45:867-872. https://doi.org/10.1016/ j.jesp.2009.03.009.

Pempek, J. A., G. M. Schuenemann, E. Holder, and G. G. Habing. 2017. Dairy calf management-A comparison of practices and producer attitudes among conventional and organic herds. J. Dairy Sci. 100:8310-8321. https://doi.org/10.3168/jds.2017-12565.

Percy, W. H., K. Kostere, and S. Kostere. 2015. Generic qualitative research in psychology. Qual. Rep. 20:76-85. https://doi.org/10 .46743/2160-3715/2015.2097.

Pereira, P. C. 2014. Milk nutritional composition and its role in human health. Nutrition 30:619-627. https://doi.org/10.1016/j.nut .2013.10.011.

Pérez-Torres, L., A. Orihuela, M. Corro, I. Rubio, M. A. Alonso, and C. S. Galina. 2016. Effects of separation time on behavioral and physiological characteristics of Brahman cows and their calves. Appl. Anim. Behav. Sci. 179:17-22. https://doi.org/10.1016/j .applanim.2016.03.010.

Perttu, R. K., B. A. Ventura, and M. I. Endres. 2020. Youth and adult public views of dairy calf housing options. J. Dairy Sci. 103:85078517. https://doi.org/10.3168/jds.2019-17727.

Placzek, M., I. Christoph-Schulz, and K. Barth. 2021. Public attitude towards cow-calf separation and other common practices of calf 
rearing in dairy farming - A review. Org. Agric. 11:41-50. https:// doi.org/10.1007/s13165-020-00321-3.

R Core Team. 2018. R: A language and environment for statistical computing. R Foundation for Statistical Computing. https://www R-project.org/.

R Studio Team. 2016. RStudio: Integrated Development Environment for R. R Studio Inc. http://www.rstudio.com/.

Rollin, B. E. 2011. Animal rights as a mainstream phenomenon. Animals (Basel) 1:102-115. https://doi.org/10.3390/ani1010102.

Roth, B. A., K. Barth, L. Gygax, and E. Hillmann. 2009. Influence of artificial vs. mother-bonded rearing on sucking behaviour, health and weight gain in calves. Appl. Anim. Behav. Sci. 119:143-150. https://doi.org/10.1016/j.applanim.2009.03.004.

Ruby, M. B. 2012. Vegetarianism. A blossoming field of study. Appetite 58:141-150. https://doi.org/10.1016/j.appet.2011.09.019.

Ryan, E. B., D. Fraser, and D. M. Weary. 2015. Public attitudes to housing systems for pregnant pigs. PLoS One 10:e0141878. https: //doi.org/10.1371/journal.pone.0141878.

Sato, P., M. Hötzel, and M. A. G. von Keyserlingk. 2017. American citizens' views of an ideal pig farm. Animals (Basel) 7:64. https:// doi.org/10.3390/ani7080064

Searle, S. R., F. M. Speed, and G. A. Milliken. 1980. Population marginal means in the linear model: An alternative to least squares means. Am. Stat. 34:216-221. https://doi.org/10.1080/00031305 1980.10483031

Slocum-Gori, S. L., and B. D. Zumbo. 2011. Assessing the unidimensionality of psychological scales: Using multiple criteria from factor analysis. Soc. Indic. Res. 102:443-461. https://doi.org/10.1007/ s11205-010-9682-8.

Statistics Canada. 2011. Canada's rural population since 1851, Census in Brief, Catalogue no. 98-310-X2011003. Accessed Jan. 12, 2021. https://www12.statcan.gc.ca/census-recensement/2011/as-sa/98 -310-x/98-310-x2011003_2-eng.cfm.

Statistics Canada. 2017. Census Profile, 2016 Census, Catalogue no. 98-316-X2016001. Accessed Jan. 12, 2021. https:// www12.statcan.gc.ca/census-recensement/2016/dp-pd/prof/index .cfm?Lang=E.

Stěhulová, I., L. Lidfors, and M. Špinka. 2008. Response of dairy cows and calves to early separation: Effect of calf age and visual and auditory contact after separation. Appl. Anim. Behav. Sci. 110:144165. https://doi.org/10.1016/j.applanim.2007.03.028.

Stěhulová, I., B. Valníčková, R. Sárová, and M. Špinka. 2017. Weaning reactions in beef cattle are adaptively adjusted to the state of the cow and the calf. J. Anim. Sci. 95:1023-1029. https://doi.org/10 $.2527 /$ jas2016.1207.

Tackie, N. O., J. R. Bartlett, and A. Adu-Gyamfi. 2015. The impact of socioeconomic factors and meat attributes on willingness to pay for locally or regionally produced livestock products in Alabama. J. Econ. Sustain. Dev. 6:140-153.

Tarazona, A. M., M. C. Ceballos, and D. M. Broom. 2019. Human relationships with domestic and other animals: One health, one welfare, one biology. Animals (Basel) 10:43. https://doi.org/10 $.3390 /$ ani10010043.

USDA. 2016. Dairy 2014-Dairy Cattle Management Practices in the United States, 2014. USDA; Animal and Plant Health Inspection Service; Veterinary Services; National Animal Health Monitoring System. Accessed Sep. 16, 2019. https://www.aphis.usda.gov/ animal_health/nahms/dairy/downloads/dairy14/Dairy14_dr _PartI_1.pdf.

Vaarst, M., M. B. Jensen, and A. M. Sandager. 2001. Behaviour of calves at introduction to nurse cows after the colostrum period. Appl. Anim. Behav. Sci. 73:27-33. https://doi.org/10.1016/S0168 -1591(01)00120-4.

van Dijk, L., A. Hayton, D. C. J. Main, A. Booth, A. King, D. C. Barrett, H. J. Buller, and K. K. Reyher. 2017. Participatory policy making by dairy producers to reduce anti-microbial use on farms. Zoonoses Public Health 64:476-484. https://doi.org/10.1111/zph .12329

Vanhonacker, F., W. Verbeke, E. Van Poucke, and F. A. M. Tuyttens. 2008. Do citizens and farmers interpret the concept of farm animal welfare differently? Livest. Sci. 116:126-136. https://doi.org/10 .1016/j.livsci.2007.09.017.

Vaske, J. J. 2008. Linking theory and concepts to survey research. Pages 17-34 in Survey Research and Analysis: Applications in Parks, Recreation and Human Dimensions. Venture Publishing, Inc.

Vasseur, E., F. Borderas, R. I. Cue, D. Lefebvre, D. Pellerin, J. Rushen, K. M. Wade, and A. M. de Passillé. 2010. A survey of dairy calf management practices in Canada that affect animal welfare. J. Dairy Sci. 93:1307-1315. https://doi.org/10.3168/jds.2009-2429.

Ventura, B. A., M. A. G. von Keyserlingk, C. A. Schuppli, and D. M. Weary. 2013. Views on contentious practices in dairy farming: The case of early cow-calf separation. J. Dairy Sci. 96:6105-6116. https: //doi.org/10.3168/jds.2012-6040.

Ventura, B. A., M. A. G. von Keyserlingk, H. Wittman, and D. M. Weary. 2016. What difference does a visit make? Changes in animal welfare perceptions after interested citizens tour a dairy farm. PLoS One 11:e0154733. https://doi.org/10.1371/journal.pone .0154733 .

Verbeke, W. 2009. Stakeholder, citizen and consumer interests in farm animal welfare. Anim. Welf. 18:325-333.

Vermeir, I., and W. Verbeke. 2006. Sustainable food consumption: Exploring the consumer "attitude - behavioral intention" gap. J. Agric. Environ. Ethics 19:169-194. https://doi.org/10.1007/s10806 -005-5485-3.

Wagner, K., K. Barth, R. Palme, A. Futschik, and S. Waiblinger. 2012. Integration into the dairy cow herd: Long-term effects of mother contact during the first twelve weeks of life. Appl. Anim. Behav. Sci. 141:117-129. https://doi.org/10.1016/j.applanim.2012.08.011.

Walker, S., S. Read, and H. Priest. 2013. Use of reflexivity in a mixedmethods study. Nurse Res. 20:38-43. https://doi.org/10.7748/ nr2013.01.20.3.38.c9496.

Weary, D. M., and B. Chua. 2000. Effects of early separation on the dairy cow and calf: 1 . Separation at $6 \mathrm{~h}, 1$ day and 4 days after birth. Appl. Anim. Behav. Sci. 69:177-188. https://doi.org/10 .1016/S0168-1591(00)00128-3.

Weary, D. M., and J. Robbins. 2019. Understanding the multiple conceptions of animal welfare. Anim. Welf. 28:33-40. https://doi.org/ 10.7120/09627286.28.1.033.

Weary, D. M., B. A. Ventura, and M. A. G. von Keyserlingk. 2016. Societal views and animal welfare science: Understanding why the modified cage may fail and other stories. Animal 10:309-317. https://doi.org/10.1017/S1751731115001160.

Wickham, H. 2016. ggplot2: Elegant Graphics for Data Analysis. Springer-Verlag.

Widmar, N. O., C. J. Morgan, C. A. Wolf, E. A. Yeager, S. R. Dominick, and C. C. Croney. 2017. US resident perceptions of dairy cattle management practices. Agric. Sci. 8:645-656. https://doi .org/10.4236/as.2017.87049.

Winder, C. B., C. A. Bauman, T. F. Duffield, H. W. Barkema, G P. Keefe, J. Dubuc, F. Uehlinger, and D. F. Kelton. 2018. Canadian National Dairy Study: Heifer calf management. J. Dairy Sci. 101:10565-10579. https://doi.org/10.3168/jds.2018-14680.

Wolf, C. A., G. T. Tonsor, M. G. S. McKendree, D. U. Thomson, and J. C. Swanson. 2016. Public and farmer perceptions of dairy cattle welfare in the United States. J. Dairy Sci. 99:5892-5903. https:// doi.org/10.3168/jds.2015-10619.

Woods, A. T., C. Velasco, C. A. Levitan, X. Wan, and C. Spence. 2015. Conducting perception research over the internet: A tutorial review. PeerJ 3:e1058. https://doi.org/10.7717/peerj.1058.

\section{ORCIDS}

L. V. Sirovica @ https://orcid.org/0000-0002-2095-1183

C. Ritter (ㄴ) https://orcid.org/0000-0001-7349-5241

D. M. Weary @ https://orcid.org/0000-0002-0917-3982

M. A. G. von Keyserlingk (1) https://orcid.org/0000-0002-1427-3152 